\title{
Biosensing Using Magnetic Particle Detection Techniques
}

\author{
Yi-Ting Chen, Arati G. Kolhatkar, Oussama Zenasni, Shoujun Xu * and T. Randall Lee * \\ Department of Chemistry and the Texas Center for Superconductivity, University of Houston, Houston, \\ TX 77204, USA; ychen75@uh.edu (Y.-T.C.); kolhatkara@yahoo.com (A.G.K.); Zenasni_sam@hotmail.com (O.Z.) \\ * Correspondence: sxu7@central.uh.edu (S.X.); trlee@uh.edu (T.R.L.); Tel.: +1-832-842-8828 (S.X.); \\ +1-713-743-2724 (T.R.L.)
}

Received: 2 July 2017; Accepted: 30 August 2017; Published: 10 October 2017

\begin{abstract}
Magnetic particles are widely used as signal labels in a variety of biological sensing applications, such as molecular detection and related strategies that rely on ligand-receptor binding. In this review, we explore the fundamental concepts involved in designing magnetic particles for biosensing applications and the techniques used to detect them. First, we briefly describe the magnetic properties that are important for bio-sensing applications and highlight the associated key parameters (such as the starting materials, size, functionalization methods, and bio-conjugation strategies). Subsequently, we focus on magnetic sensing applications that utilize several types of magnetic detection techniques: spintronic sensors, nuclear magnetic resonance (NMR) sensors, superconducting quantum interference devices (SQUIDs), sensors based on the atomic magnetometer (AM), and others. From the studies reported, we note that the size of the MPs is one of the most important factors in choosing a sensing technique.
\end{abstract}

Keywords: magnetic particles; spintronic sensors; GMR; NMR; SQUID; atomic magnetometer; molecular sensing

\section{Introduction}

Magnetic particles (MPs) in the nanometer to micrometer size range are used extensively in modern bioanalytical methods and biomedical therapies. Magnetic detection offers the distinct advantage of low background interference compared to optical and electrical approaches [1,2]. Due to their facile functionalizability, MPs have the potential of integrated design for a wide range of purposes, such as signal markers, separation platforms, force transducers, and sensing devices. Additionally, MPs have been used as imaging agents, heat generators, and drug carriers [1,3,4]. Moreover, the ability to measure biological interactions using a magnetically labeled target (i.e., a ligand-receptor complex) furthers our understanding of the interactions between biomolecules, which allows advancements in the design of emerging diagnostic techniques.

In general, designing MPs for a specific application involves several processes, including: (i) synthesizing MPs of a suitable size, (ii) modifying the MPs with a biocompatible linker and suitable ligands, (iii) tailoring the size of the MPs and ligands to optimize the magnetic properties for the selected application, and (iv) identifying an optimal magnetic detection technique to test and use the MPs. Current studies have provided us with parameters to synthesize MPs selectively from the nanometer to the micrometer size range. For in vivo biomedical imaging and drug delivery, the size of the MPs should be below $100 \mathrm{~nm}$ to ensure endocytosis into target organs and cells [5]. However, for biological sensing, larger MPs give stronger signals owing to their higher magnetization [4] and are preferred. Additionally, surface functionalization is critical to protect the magnetic core and to attach it to target molecules. Numerous studies have reported the effect that coating MPs with shells and functional ligands have on generating successful biomedical applications [3,6-8]. 
The last step in the design of a MP system is selecting an analytical technique to detect the magnetic signal. There are several types of magnetic detection techniques, including but not limited to spintronic sensors based on giant magnetoresistance (GMR), tunnel magnetoresistance (TMR), and planar Hall effect (PHE) sensors, superconducting quantum interference devices (SQUIDs), atomic magnetometers (AMs), nuclear magnetic resonance (NMR) systems, fluxgate sensors, Faraday induction coil sensors, diamond magnetometers, and domain walls-based sensors [3,9-19]. These techniques have been used to measure the magnetic response in the form of susceptibility, relaxation, remanence, MP-induced proton NMR, and even frequency mixing [17,20-26]. Also, these detection techniques can be categorized as either volumetric-based or surface-based [6]. The volumetric-based sensors, such as PHE sensors and NMR systems, provide simple and rapid sample preparation and detection. Separately, surface-based sensors, such as GMR and TMR, offer a lower detection limit (single particle) due to the short distance between the MPs and the sensor; however, these techniques typically require laborious sample and/or substrate preparation. Sensitive magnetometers, such as SQUIDs and AMs, can be used in either mode, depending on the specific applications. To date, several types of magnetic sensors have been developed and integrated with various other techniques to provide biosensing for a wide range of applications [12-14,25]. Nevertheless, optimizing MPs for specific applications and selecting appropriate detection methods remain challenging for the magnetic nanotechnology community due to the increasing demands of detection sensitivity, molecular specificity, and application complexity. Our report describes the synthesis and functionalization of MPs and their subsequent use for detection. To provide context, we briefly discuss the basic concepts in magnetism and highlight the critical magnetic parameters that can be manipulated based on the application targeted.

\section{Basic Concepts in Magnetism and Use of Magnetic Particles in Biological Applications}

The magnetic properties of nano- and micron-sized magnetic materials differ from those of the corresponding bulk magnetic materials. Typically, MPs are classified (see Figure 1a) as paramagnetic, ferromagnetic, ferrimagnetic, antiferromagnetic, or superparamagnetic based on their magnetic behavior in the presence and absence of an applied magnetic field [27-29].

a)

\begin{tabular}{|c|c|c|c|}
\hline $\begin{array}{l}H=0 \\
\bigcirc \bigcirc 00 \\
\bigcirc \bigcirc 00 \\
\bigcirc \bigcirc 00 \\
\bigcirc \bigcirc \bigcirc \bigcirc \\
\text { Diamagnetic }\end{array}$ & $\begin{array}{l}\stackrel{H}{\vec{\theta} \Theta \Theta} \\
\Theta \Theta \Theta \Theta \\
\Theta \Theta \Theta \Theta \\
\Theta \Theta \Theta \Theta \\
\text { materials }\end{array}$ & \multicolumn{2}{|c|}{ 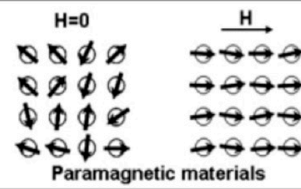 } \\
\hline 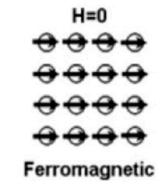 & $\begin{array}{c}\oplus \\
\oplus \\
\oplus \\
\oplus \\
\text { Ferrin }\end{array}$ & $\begin{array}{l}0 \\
\oplus \oplus \\
\oplus \oplus \\
\oplus \oplus \\
\oplus \oplus \\
\oplus \oplus \\
\text { unetic }\end{array}$ & $\begin{array}{c}H=0 \\
\theta \theta \theta \theta \\
\theta \theta \theta \theta \\
\theta \theta \theta \theta \\
\theta \theta \theta \theta \\
\text { Antiferromagnetic }\end{array}$ \\
\hline
\end{tabular}

b)

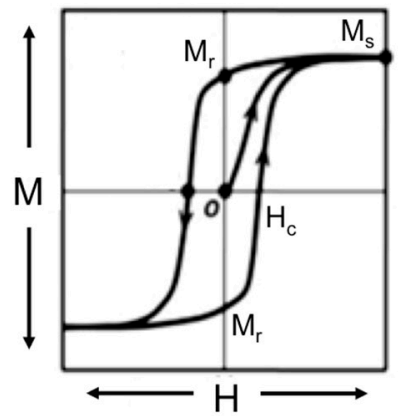

c)

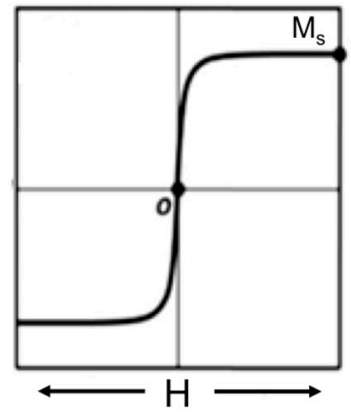

Figure 1. (a) Illustration of the behavior of the magnetic dipole moments in five types of magnetic materials with and without an external magnetic field $(\mathrm{H})$. (b) Schematic of typical magnetization curves generated by an applied magnetic field. The general hysteresis loop shows the relationship of magnetization versus the applied magnetic field. The curved slope defines the magnetic susceptibility of the material. (c) A non-hysteretic magnetic curve of a superparamagnetic material. Reproduced with permission from [28], copyright 2007 Wiley, and from [8], copyright 2009 The Royal Society of Chemistry.

Figure $1 \mathrm{~b}$ illustrates the fundamental magnetic properties of magnetic materials, including magnetic particles. In the presence of an external magnetic field, the magnetic moment of the material is aligned along the direction of the external field, where the maximum magnetization is labeled as the 
saturation magnetization $\left(\mathrm{M}_{\mathrm{s}}\right)$. At zero magnetic field, the magnetization of these materials tends to retain the previous direction and magnetization, called the "remanent magnetization" $\left(\mathrm{M}_{\mathrm{r}}\right)$. Reversing the direction of the external magnetic field brings the ferromagnetic domains into a compensated state, and the overall effective magnetization appears to be zero. The field strength required to demagnetize the MPs (forcing the magnetization to be zero) is defined as the coercivity $\left(\mathrm{H}_{\mathrm{c}}\right)$. Figure 1c shows a unique paramagnetic feature of MPs called superparamagnetism. For a single domain MP at a sufficiently high temperature (i.e., the blocking temperature), there is sufficient thermal energy to overcome the anisotropy barrier, which randomizes the magnetization. Therefore, in the absence of external magnetic fields, MPs exhibit negligible remanent magnetization. However, with increasing external magnetic fields, the magnetization of the MPs grows, similar to paramagnetic materials $[8,29]$.

MPs have been used in a variety of biological applications [4,29]; herein, we review and correlate certain applications to the critical magnetic properties, such as, $\mathrm{M}_{\mathrm{s}}, \mathrm{H}_{\mathrm{c}}$, blocking temperature, and magnetocrystalline anisotropy [27]. One of the key factors in magnetic biosensing is magnetic susceptibility for small fields and saturation magnetization $\left(\mathrm{M}_{\mathrm{s}}\right)$ for large fields: a stronger magnetic moment (high $\mathrm{M}_{\mathrm{s}}$ ) of labeled MPs offers higher sensitivity toward a sensor platform fabricated with its conjugate biomolecule. The $\mathrm{M}_{\mathrm{s}}$ in MPs is also related to the translational vector for spatial movements, where higher $M_{s}$ provides a stronger translational attractive force when exposed at a large magnetic gradient [4]. Moreover, a larger $\mathrm{M}_{\mathrm{s}}$ often corresponds to a larger mass for the MPs. Several multimodal techniques have been developed that treat MPs as both force transducer and signal provider. For example, the force-based technique of magnetic tweezers and force-induced remanent magnetization spectroscopy (FIRMS) use MPs to induce dissociation of ligand-receptor pairs and then quantify the magnetic signal $[25,30]$.

As noted above, the size of particles also plays an important role in determining their magnetic properties. The $\mathrm{M}_{\mathrm{S}}$ of MPs usually increases with an increase of particle size due to a decrease in the surface effect in which the spins on the surface can differ from those in the bulk [4,31]. Furthermore, the homogeneity of MPs is uniquely important in determining the translational force for the separation of biomolecules and magnetic manipulation in sensing applications [32-34]. MPs can be held in a saturated state only by an external field larger than the demagnetizing field. Once this external field is removed, the magnetostatic energy associated with the saturated state breaks the particles into domains and reduces the magnetization $[11,29,35]$. For most magnetic materials, the single domain size usually falls in the range of $10-50 \mathrm{~nm}$ and is related with their intrinsic properties (such as magnetization saturation, magnetic anisotropy constant, and the exchange stiffness) [1]. When the size of MPs becomes smaller than one single domain, the MPs become superparamagnetic. In large MPs composed of multi-domain structures, the magnetization separated by domain walls is retained.

Relaxation is a unique magnetic phenomenon when the magnetic dipoles lose their effective moments. This phenomenon occurs via two different relaxation mechanisms: (i) Néel relaxation, which originates from spin-spin relaxation through the rotation of the magnetic moment within the MPs overcoming the anisotropy energy barrier, and (ii) Brownian relaxation, which comes from the mechanical rotation of the MPs. Relaxation measurements are commonly used in magnetic detection. Typically, Néel relaxation is more dominant for small MPs (range $<15 \mathrm{~nm}$ for iron oxide) and depends on the magnetocrystalline anisotropy $[2,27,36]$.

Relaxation processes occurring in MPs is harnessed in magnetic hyperthermia therapy applications. In this therapy, the generation of heat occurs either by repeated Néel and Brownian relaxation processes or by hysteresis loss when the MPs are exposed to an alternating magnetic field. The heat is then transferred to the surroundings, which provide sufficient energy to treat, for example, targeted tumor tissue. The generation of heat is highly sensitive to the magnetic properties, such as $\mathrm{M}_{\mathrm{s}}, \mathrm{H}_{\mathrm{c}}$, magnetic anisotropy $(\mathrm{K})$, particle size, and surrounding environment [1,4,36]. In drug-delivery applications, the MPs are visualized using magnetometer imaging and then guided in the presence of an external magnetic field; the heat is used to trigger drug release or for tissue ablation. The external 
magnetic field decays with distance, and high-M $\mathrm{M}_{\mathrm{S}}$ MPs are preferred since they can be easily magnetized in a weak field [4].

MPs are also used to alter the relaxation of nuclear spins, based on which NMR technique is used to detect the MPs. When exposed to an external magnetic field, MPs create small local magnetic fields that make the surrounding protons undergo faster spin-spin relaxation times $\left(\mathrm{T}_{2}\right)$. The critical magnetic parameter for imaging is the transverse relaxation rate $\left(R_{2}\right)$, which is defined as $R_{2}=1 / T_{2}$. It has been demonstrated that MPs can induce high $T_{2}$ relaxivity, which is defined as the $R_{2}$ difference in the presence vs. the absence of the MPs divided by the particle concentration $[4,37]$. Higher relaxivities can be achieved using MPs with larger sizes and higher $\mathrm{M}_{\mathrm{S}}$ values [38]. MPs as contrast agents in magnetic resonance imaging (MRI) studies and as labeling and signal transducers in biosensing studies are excellent examples of the effect of MPs on nuclear spin relaxation $[2,7,37,39,40]$.

\section{Synthesis, Functionalization, and Biological Conjugation of Magnetic Particles}

After highlighting the importance of various magnetic properties and the role of size as well as composition, this section summarizes factors that are evaluated during the design of appropriate MPs for specific bio-applications (Figure 2). The process involves (1) the synthesis of MPs having a desired size, (2) functionalization with biocompatible ligands having functional or reactive groups, and (3) conjugation with the target biological species. The key parameters include the size of the MPs (both core and hydrodynamic sizes), chemistry of surface functionalization, and the magnetic response to the sensor. In this section, we describe the synthesis, functionalization, and bioconjugation steps in detail.

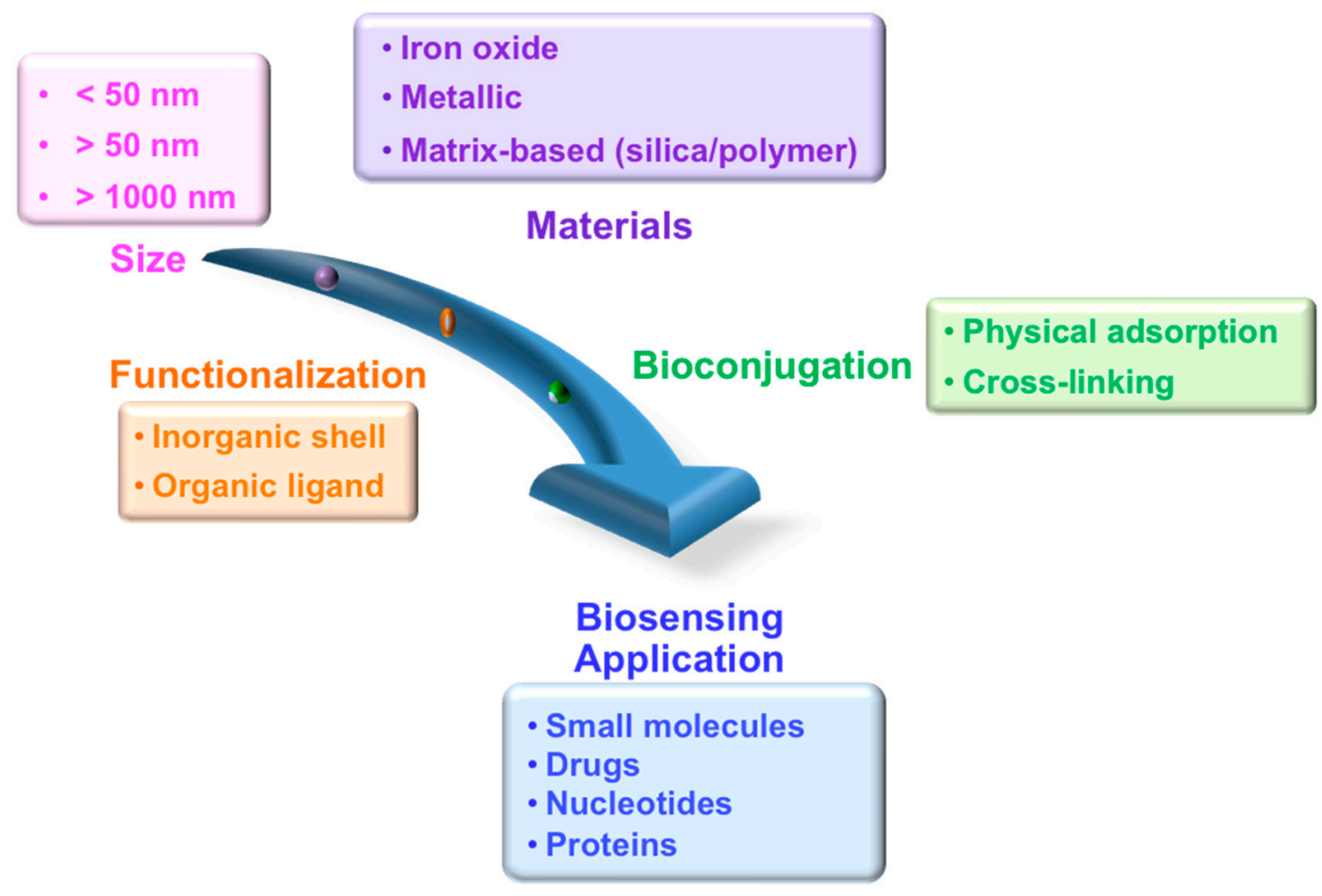

Figure 2. Design of magnetic particles for biosensing.

\subsection{Synthesis of Magnetic Particles}

The synthesis of various types of MPs has been extensively studied [2,7,8,41]. We will focus on the two main types of MPs: (1) single-core MPs (ferrites and other metallic cores), and (2) matrix-dispersed MPs. Table 1 summarizes the different methods used to synthesize MPs as a function of their sizes and compositions. 
Table 1. General Methods for the Synthesis of Magnetic Particles.

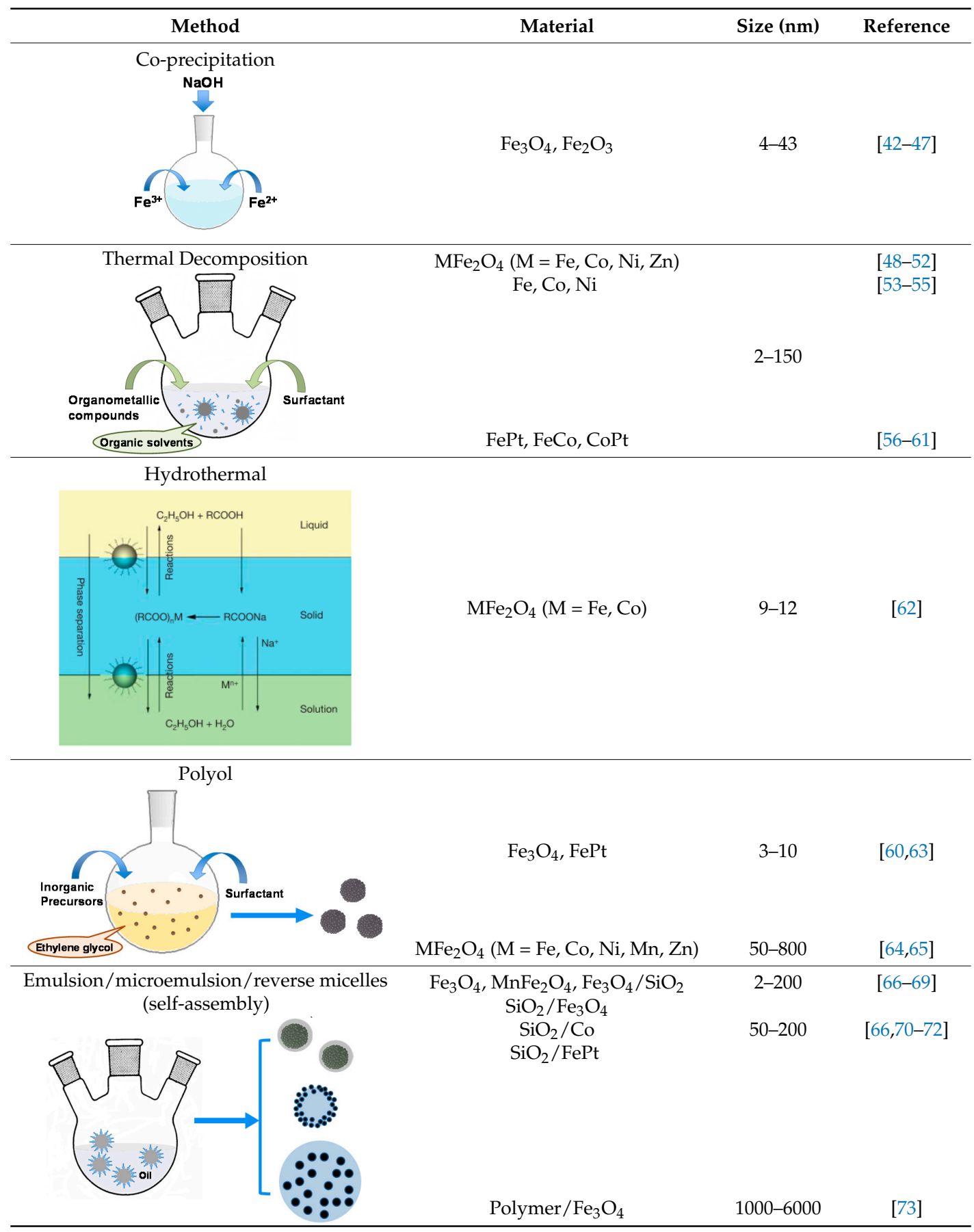

\subsubsection{Single-Core Magnetic Particles}

Ferrites: Iron oxide MPs, such as magnetite $\left(\mathrm{Fe}_{3} \mathrm{O}_{4}\right)$ and maghemite $\left(\gamma-\mathrm{Fe}_{2} \mathrm{O}_{3}\right)$, are particularly appealing due to their magnetic properties, tunable size, and biocompatibility $[37,41,74,75]$. Numerous chemical methods have reported the synthesis of iron oxide and metal-substituted ferrite MPs. Commonly used wet chemistry methods of synthesis include co-precipitation, thermal decomposition, and hydrothermal.

Co-precipitation processes utilize selected stoichiometric amounts of ferrous $\left(\mathrm{Fe}^{2+}\right)$ and ferric $\left(\mathrm{Fe}^{3+}\right)$ salts in an alkaline solution in conjunction with a water-soluble surface coating material, such as polyethylene glycol (PEG), where the coating provides colloidal stability and biocompatibility. The size 
and properties of the MPs can be controlled by tuning the reducing agent concentration, $\mathrm{pH}$, ionic strength, temperature, iron salts source, or $\mathrm{Fe}^{2+} / \mathrm{Fe}^{3+}$ ratio. However, this approach leads to relatively large size distributions [3].

In the thermal decomposition method, organometallic complexes and metal precursors such as iron cupferronate, iron acetylacetonate, and iron oleate are decomposed at elevated temperatures [48-50]. The size and shape of MPs can be tailored by varying the reaction conditions, such as the type of organic solvent, heating rate, surfactant, and reaction time. This method leads to narrow size distributions of MPs in the size range 10-100 $\mathrm{nm}[41,49]$ and is especially useful since it can be extended to the synthesis of metal-doped ferrite MPs $\left(\mathrm{MFe}_{2} \mathrm{O}_{4}, \mathrm{M}=\mathrm{Co}, \mathrm{Fe}, \mathrm{Ni}\right.$, and $\left.\mathrm{Zn}\right)$ by using additional divalent transition metal precursors. The substitution of $\mathrm{Fe}^{2+}$ by other metals offers an opportunity to boost the saturation magnetization [51]. The presence of a hydrophobic coating during the synthesis process warrants an additional step of ligand exchange so the MPs can be dispersed in water for further uses.

The hydrothermal method involves liquid-solid-solution phase transfer for the synthesis of variety of nanoparticles including iron oxide nanoparticles [62]. As in the case of thermal decomposition, the polyol-hydrothermal reduction method leads to water-dispersed MPs in the size range from tens to several hundred nanometers [64]. The solvent system, reducing agent, and type of surfactant are some of the parameters that can be used to tune the size and the surface-functionalization of iron oxide MPs [65]. In the reverse water-in-oil micelle method, which involves aqueous nanodroplets of iron precursors, a microemulsion is formed that is stabilized by a surfactant in the oil phase. Then magnetic nanoparticles can be obtained by precipitation $[68,69]$. The combination of microemulsion and silica sol-gel has been reported to assemble small iron oxide nanocrystals, which are obtained via co-precipitation into larger magnetic particles of more than $100 \mathrm{~nm}$ in diameter [76].

Metallic (Elemental): Metallic MPs possess high saturation magnetization and are either monometallic (e.g., $\mathrm{Fe}, \mathrm{Co}$, or Ni) or bimetallic (e.g., FePt and FeCo). These metallic MPs are often overlooked in biological applications due to their chemical instability and their toxicity; they typically require an external coating to overcome these disadvantages. The thermal decomposition of metal precursors and metal reduction routes are widely used for the synthesis of metallic MPs and bimetallic MPs [53,54]. For example, a common route employed for the synthesis of iron oxide MPs involves the thermal decomposition of iron pentacarbonyl $\left(\mathrm{Fe}(\mathrm{CO})_{5}\right)$ [55]. The synthesis of cobalt MPs utilizes the reduction of dicobalt octacarbonyl $\left(\mathrm{Co}_{2}(\mathrm{CO})_{8}\right)$ by $\mathrm{Al}\left(\mathrm{C}_{8} \mathrm{H}_{17}\right)_{3}$ in toluene [53].

Popular alloy MPs, including FeCo and FePt, have found use in biological applications $[2,39,56]$. Physical methods for the synthesis of alloy MPs include vacuum-deposition and gas-phase evaporation. However, physical methods suffer from certain limitations, such as aggregation, wide size distribution, and poor colloidal stability [77]. In contrast, wet chemical synthesis offers an effective route for the preparation of monodisperse bimetallic MPs. For example, FeCo MPs with high saturation magnetization (reported $207 \mathrm{emu} / \mathrm{g}$ ) are suitable for biomedical applications and can be synthesized via the reduction of $\mathrm{Fe}^{3+}$ and $\mathrm{Co}^{2+}$ salts $[53,57]$. Furthermore, FeCo nanocubes can be obtained by the liquid-phase reduction of $\mathrm{Fe}^{2+}$ and $\mathrm{Co}^{2+}$ by hydrazine in the presence of poly(ethylene glycol) and cyclohexane to give sizes tunable from 68 to $260 \mathrm{~nm}$ edge length $[78,79]$. For FePt MPs, the most common method involves the thermal decomposition of iron pentacarbonyl $\left(\mathrm{Fe}(\mathrm{CO})_{5}\right)$ or thermal reduction of iron salts (e.g., iron(II) chloride) combined with the reduction of platinum(II) acetylacetonate $\left(\mathrm{Pt}(\mathrm{acac})_{2}\right)$ to give MPs with diameters that range from 3 to $9 \mathrm{~nm}[56,58]$. By varying the ratio of stabilizer (oleylamine, oleic acid, or octadecene) to metal precursor, the shape of the FePt MPs can be tuned to nanowires, nanorods, or nanocubes [59,60]. Another synthesis route to obtain FePt MPs proceeds via the polyol process, which involves the co-reduction of the metal precursors $\mathrm{Fe}(\mathrm{acac})_{3}$ and $\mathrm{Pt}(\mathrm{acac})_{3}$ in 1,2-hexadecanediol [80]. 


\subsubsection{Matrix-Dispersed Magnetic Particles}

In addition to single metallic or metallic oxide core MPs, multi-core MPs, multilayers of magnetic materials and nonmagnetic materials, as well as the coating of silica or polymer cores with magnetic shells have also been reported [81]. Commonly used nonmagnetic core particles include silica and various polymers. These cores, in comparison to metallic oxide or metallic MPs, provide several advantages including narrow size distributions within a wide range of possible sizes, high chemical stability, and facile functionalization with various targets. One type of architecture consists of a dielectric silica core coated with a magnetic shell ( $\mathrm{Co}, \mathrm{FePt}$, or $\left.\mathrm{Fe}_{3} \mathrm{O}_{4}\right)$ together with a stabilizer (silica shell or polyelectrolyte layer) [70-72]. For example, the layer-by-layer synthesis of gold-coated silica-core magnetic MPs is shown in Figure 3a-c [72]. Mesoporous MPs, consisting of a silica/polymer framework with encapsulated MPs, is another useful design for multifunctional applications combining MR imaging, optical fluorescence imaging, cell targeting, and drug-delivery capability [82]. The microemulsion method was used to synthesize such silica particles loaded with iron oxide MPs via reverse micelles, and polymer particles containing iron oxide aggregates via swelling processes [66,73]. Magnetic materials embedded into a polymer matrix using the latter approach offers good size control up to $6 \mu \mathrm{m}$ in diameter. Figure $3 \mathrm{~d}-\mathrm{f}$ gives an example of the swelling procedure used for the synthesis of poly(divinyl benzene) infused with MPs [73]. Commercially available, matrix-dispersed MPs include styrene-based particles with $5-20 \%$ of crystalline iron oxide [83]. The performance and sensitivity of these commercial magnetic microspheres in various applications has been demonstrated using magnetic detection techniques $[12,25,84]$.

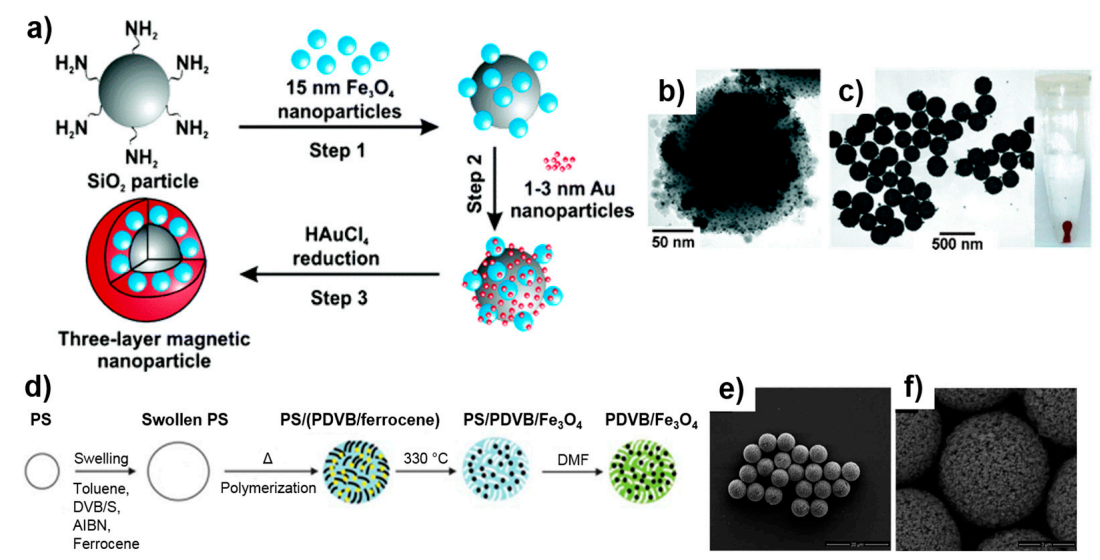

Figure 3. Examples of preparation methods for MPs embedded in silica and polymer matrices: (a) layer-by-layer synthesis of gold-coated silica-core MPs, (b) TEM image of $\mathrm{SiO}_{2} @ \mathrm{Fe}_{3} \mathrm{O}_{4} @ \mathrm{Au}_{\text {seeds }}$ (c) MPs attracted to the vessel wall by a magnet, (d) preparation of polymer composite magnetic particles by the swelling method, and (e,f) SEM image of polymer-embedded MPs. Reproduced with permissions from [72], copyright 2005 American Chemical Society, and from [73], copyright 2012 Royal Society of Chemistry.

\subsubsection{Toxicity}

Due to the potential applications of MPs in biomedical and biological research, the toxicity of MPs is a concern that must be addressed. Since most of the MPs are composed of transition metals, the leaching and biodegradation of MPs are likely to cause the release of free metal ions, leading to the generation of reactive oxygen species (ROS) and their related undesirable effects. Exposure to MPs can lead to (in addition to the generation of ROS) inflammation, impaired mitochondrial function, DNA damage, and severe toxicity at $\sim 60 \mathrm{mg}$ iron/ $\mathrm{kg}$ animal $[85,86]$. Notably, ROS can trigger undesired defense mechanisms in the body, which are commonly considered to be the main cause of toxicity 
from MPs. The coating on MPs can inhibit the ROS process $[87,88]$; for example, iron oxide MPs can be rendered biocompatible with suitable coating materials, such as silica, gold, or PEG.

The toxicity of MPs depends on the size, chemical composition, surface charge, and particle-induced reactions. Smaller MPs typically have a larger surface area-to-volume ratio and are chemically more reactive than their larger counterparts $[1,89]$. Hydrodynamic size is another parameter that affects the functionality and permeation in biological media. The surface charge and coating can alter the hydrodynamic size, which can be tuned to optimize functionality. In addition, the interface between MPs and biological systems is one of the critical factors influencing the biosafety of nanoparticles [82,89]. In short, designing a suitable surface coating on the MPs of chosen size and shape will define the interactions between the particles and biological molecules and their biocompatibility.

\subsection{Functionalization of Magnetic Particles}

The stabilization of MPs is crucial for any application. Preventing agglomeration or precipitation stands as a challenge due to the attractive van der Waals and magnetic inter-particle forces. Charged and/or bulky ligands can be used to provide forces of electrostatic and steric repulsion, respectively, for the MPs. Such coatings not only protect the magnetic cores, but also can render them biocompatible (minimizing toxicity effects), while also providing a chemical handle for the further conjugation of affinity ligands, such as proteins or DNA. Various types of inorganic and organic functionalization strategies are described below.

\subsubsection{Inorganic Shell Coatings: Silica and Gold}

Inorganic materials as protective shell coatings have become an attractive approach to shield against environmental influence. The most common approach to encapsulate the magnetic nanoparticles is by using a core-shell structure comprised of biocompatible silica or gold to cover the magnetic nanoparticles [39]. These popular coating materials provide protection against chemical oxidation or degradation of the magnetic core and prevent potentially toxic leakage of metal ions from the magnetic core. Additionally, the shell provides a useful platform to modify the particles with various ligands (e.g., the gold shell binds to thiols and related compounds). Other inorganic materials used as coatings include titanate or silver [90-92]. For example, silver-coated iron oxide MPs were synthesized and integrated with carbon paste for use as an immunosensor [92]. In this review, we have focused on silica and gold shells due to the ease and versatility in their ensuing functionalization.

Silica: Silica shells have been widely exploited due to the convenience of the coating procedure and subsequent functionalization. The synthesis of silica-coated magnetic nanoparticles by the Stöber method using sol-gel principles has been known for many years [93]. Typically, tetraethoxysilane (TEOS) is used to produce the coating on various magnetic cores with controllable thicknesses [94]. To deposit silica on MPs, TEOS hydrolysis under basic conditions (e.g., aqueous ammonium hydroxide solution) is performed to condense and polymerize TEOS into a silica shell on the surface of the magnetic core. The coating thickness can be controlled by adjusting the relative concentrations of ammonium hydroxide, TEOS, and water, or by using ultrasound treatment $[95,96]$. The thickness of the silica coating influences the relaxation properties of the MPs [42]. Polyvinylpyrrolidone (PVP) is a common agent used in the coating procedure to stabilize the MPs in aqueous solution and to prevent agglomeration and multicore coating [42,96,97]. Alloy magnetic nanoparticles, FeCo and CoPt, have also been successfully coated with silica [61,79]. A modified Stöber method combining (3-aminopropyl)trimethoxysilane (APTMS) and TEOS was used to coat silica on cobalt MPs [98].

Another popular approach for coating with silica is the Philipse method, in which a silica shell is formed by depositing sodium silicate on the magnetic core [43]. However, since the first layer of silica coating is usually too thin, a second layer of silica is deposited via utilization of the Stöber method $[43,44,99]$. Yang and co-workers, for example, prepared silica-coated, multi-core iron oxide MPs via the Philipse and Stöber methods under ultrasonic treatment [44]. Separately, the reverse 
microemulsion method is another popular strategy for coating with silica and has been used with surfactants such as Igepal CO-520 to give silica shell thicknesses in the range of 5-20 $\mathrm{nm}$ [100].

One of the greatest advantages of coating with silica is the ability of the silica-coated MPs to bind covalently with versatile functional molecules and surface-reactive groups. Important reagents include amino-terminated silanes, such as (3-aminopropyl)trimethoxysilane (APTMS), and alkene-terminated silanes, such as (3-methacryloxypropyl)trimethoxylsilane, which are then available to grow a polymeric shell on the surface of silica-coated MPs through crosslinking polymerization [33,99]. However, a disadvantage of the silica shells and/or silane ligands is their instability under harsh conditions, where Si-O-Si bonds are readily hydrolyzed under basic conditions [82,101,102]. Importantly, this drawback can turn to an advantage by developing a mesoporous silica shell through careful control of the basic conditions and by adding a surfactant, such as cetyl trimethylammonium bromide (CTAB). The mesoporous silica coating can be used as a drug-delivery or enzyme-delivery cavity; it offers the ability to load and release species such as drugs or proteins in MPs with tunable silica pore sizes [101-104]. For example, Yue and co-workers synthesized mesoporous magnetic microspheres and demonstrated the immobilization of different sizes of enzymes [101].

Gold: Gold as a protective shell is inert and biocompatible, and it has a unique binding specificity with alkanethiols $[105,106]$. Gold shells provide additional functionality in diagnostics and therapeutics via the strong absorption of light in the visible and near infrared [106-108]. The surface plasmon effect offers multifunctional therapeutic heating for gold-coated MPs [103,106-108]. Notably, the synthesis of gold-coated iron oxide nanoparticles can be accomplished using chemical methods, reversed microemulsion, and laser-promoted methods [81,107]. Gold-coated MPs are prepared either by directly coating gold on the MP core or by using silica as an intermediate layer for gold coating $[81,108]$.

Reduction is the most commonly used method to deposit gold shells on MPs. Metal oxide magnetic cores or silica-coated magnetic cores are first functionalized with APTMS, and then 2-3 nm gold nanocrystal seeds from chloroauric acid $\left(\mathrm{HAuCl}_{4}\right)$ are electrostatically attached to the surface. Then mild reducing agents, such as sodium citrate or tetrakis(hydroxymethyl)phosphonium chloride (THPC), effect the reduction of $\mathrm{HAuCl}_{4}$ on the MP oxide surface, giving rise to the gold shell $[90,107,108]$. The compound, gold(III) acetate $\left(\mathrm{Au}\left(\mathrm{OOCCH}_{3}\right)_{3}\right)$, serves as an alternate gold source for this reduction method [105]. Several bio-applications, such as MRI, fluorescence imaging, and catalysis are based on gold-coated MPs [106,109]. Reverse micelles have also been used to grow gold shells on metallic magnetic cores, such as nickel and iron $[67,110]$.

The multiple advantages of silica and gold shells have attracted researchers to develop multifunctional MPs $[103,104]$. Figure 4 illustrates the various projected applications of multifunctional $\mathrm{Fe}_{3} \mathrm{O}_{4} @ \mathrm{Au} @ \mathrm{mSiO}_{2} \mathrm{MPs}$ [103].

a)

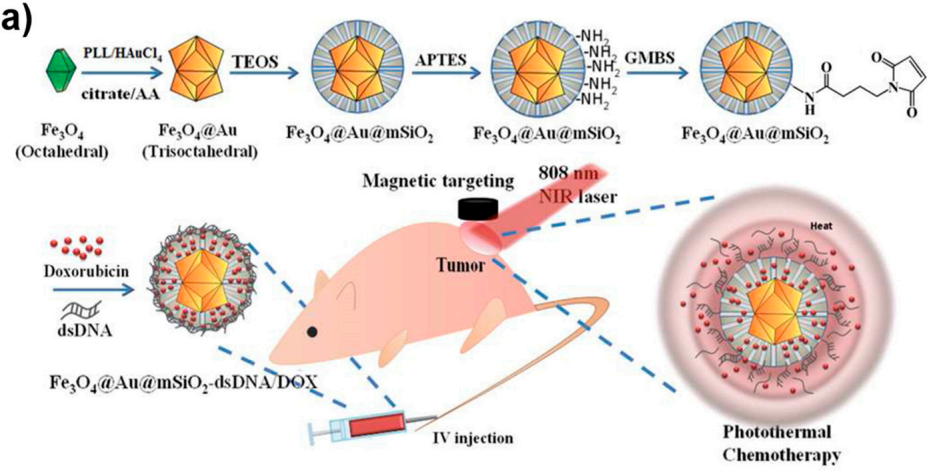

b)
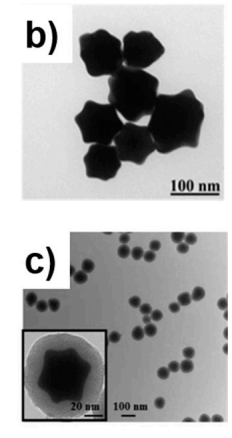

Figure 4. (a) Illustration of the preparation of $\mathrm{Fe}_{3} \mathrm{O}_{4} @ \mathrm{Au} @ \mathrm{mSiO}_{2}$-dsDNA/DOX nanoparticles for in vivo treatment of cancer cells, (b) TEM image of $\mathrm{Fe}_{3} \mathrm{O}_{4} @ \mathrm{Au}$, and (c) TEM image of $\mathrm{Fe}_{3} \mathrm{O}_{4} @ \mathrm{Au} @ \mathrm{mSiO}_{2}$. Reproduced with permission from [103], copyright 2014 American Chemical Society. 


\subsubsection{Functionalization with Organic Ligands}

The functionalization of MPs with organic ligands can be performed in-situ or post-synthesis. The in-situ method provides functional ligands on MPs during the synthesis step, and the MPs are immediately ready for further conjugation and use [111]. For example, MPs can be tethered with terminal hydroxyl groups $(-\mathrm{OH})$, amino groups $\left(-\mathrm{NH}_{2}\right)$, and carboxyl groups $(-\mathrm{COOH})$ by varying the surfactant (e.g., dextran, chitosan, or poly(acrylic acid)) used in the hydrothermal synthesis [111]. However, the in-situ method cannot be applied universally for all possible ligands. In contrast, the post-synthesis method allows functionalization of customized ligands on almost any MP surface.

Ligand addition and ligand exchange are the two primary strategies for the post-synthesis functionalization of MPs. Ligand addition can be achieved through the adsorption of amphiphilic molecules that contain both a hydrophobic segment and a hydrophilic component to form a double-layer structure [8]. On the MP surface, the metallic atoms are electron deficient; consequently, the surfaces have an affinity for electron-rich functional groups such as amines, carboxylates, hydroxyls, phosphates, and thiols. The ligand-exchange process directly replaces the original surfactants (or ligands) with new functional ligands. The new ligands usually contain a functional group that is capable of binding on the MP surface via either strong chemical bonding or electrostatic attraction, and another functional group for stabilization in water and further bio-functionalization. For hydrophobic MPs, ligand exchange is the main approach to enhance MP dispersibility in water by replacing the hydrophobic capping ligands with hydrophilic ligands, such as polyethylene glycol (PEG) or polyvinylpyrrolidone (PVP) or selected organosilanes and thiols [42,46,52]. For example, the hydrophobic ligands on $6 \mathrm{~nm} \mathrm{Fe}{ }_{3} \mathrm{O}_{4} \mathrm{MPs}$ were replaced with organosilane terminated with $-\mathrm{NH}_{2}$, $-\mathrm{SH}$, and - $\mathrm{COOH}$ groups for further conjugation with fluorescent dyes [46]. Another study utilized nine types of silane ligands (terminated with amine, short aldehyde, acrylate, isocyanate, thiol, PEG, long aldehyde, cyano, or carboxylate groups) and exchanged with oleic acid present on the $\mathrm{CoFe}_{2} \mathrm{O}_{4}$ MPs [52]. We have broadly classified the ligands as "small monomeric" and "polymeric" for ease of discussion.

Small Monomeric Ligands: Suitable molecular species that enhance ionic stability and further chemical modification are typically chosen as ligands to adorn the MP surfaces. The advantages of small molecules as ligands include tunable coverage on the MPs, a small hydrodynamic radius that is necessary for endocytosis, and a simple reaction procedure. However, small molecule ligands must be carefully evaluated since they might offer an insufficient steric barrier for colloidal stability if the molecular film is too thin. Functional groups including carboxylates, phosphates, and catechol are known to bind to the surface of metal oxides [47,112].

The siloxane group has a strong affinity for surfaces enriched in hydroxyl groups such as metal oxide MPs or silica-coated MPs. Commercially available, small silane ligands work as a bridge to link MPs and various functional ligands, including amines, carboxylates, thiols, and epoxides [33,34,102,113-115]; these functional ligands serve as effective linkers for further biological applications, such as protein immobilization. The silane APTMS is perhaps the ligand most widely used to modify $\mathrm{Fe}_{3} \mathrm{O}_{4}$ MPs, which can subsequently be conjugated with molecules such as fluorescence dyes for use in immunoglobulin (IgG) immunoassays [33]. An example of thiol-based functionalization is provided by 3-mercaptopropyltrimethoxysilane (MPTMS)-modified MPs conjugated with maleimide-functionalized streptavidin; these MPs have been used as MRI $T_{2}$ imaging contrast agents and were used to kill HER2+ cells selectively [116]. Li and co-workers used various types of silane-functionalized MPs to conjugate with protease, followed by an evaluation of the enzymatic activity [114]. For the preparation of carboxylate-terminated MPs, the silane ligands N-(trimethoxysilylpropyl)ethylenediaminetriacetic acid (TMS-EDTA) [117] and (triethoxysilylpro-pyl)succinic anhydride have been used to functionalize the surfaces of the MPs [113,118].

The functional groups phosphonic acid and catechol provide good stability when bound to MP surfaces, and the hydrophilic tail groups offer dispersion in biological media and 
bioconjugation [47,112,119-123]. Amino-terminated phosphonic acids on iron oxide MPs have been evaluated for cellular uptake and cytotoxicity [124]; separately, multifunctional mesoporous silica MPs were functionalized with 3-(trihydroxysilyl)propyl methylphosphonate for dispersion in aqueous solution, drug delivery, MR imaging, fluorescence imaging, magnetic manipulation, and cell targeting [82]. Of the catechol-based ligands, dopamine is one of the most attractive due to the stability of its adducts $[112,119]$. Iron oxide MPs modified with zwitterionic dopamine sulfonate groups have demonstrated enhanced $\mathrm{pH}$ stability and the prevention of nonspecific interactions with proteins [32]. Several other anchoring ligands, such as dihydroxyhydrocinnamic acid, citric acid, and thiomalic acid have been used to enhance dispersion of the functionalized MPs in water $[63,125,126]$.

Polymeric Ligands: Polymeric functionalization is a popular method for modifying nanoparticles because the polymer coating creates a steric barrier to prevent agglomeration and also offers the surface functionality. One concern for polymeric functionalization is the increase of hydrodynamic radius, which might hinder certain biological applications. The length and molecular weight of the polymers need to be carefully evaluated based on the intended use. The attachment of polymeric chains on MPs can occur via physical adsorption and/or covalent bonding. Both natural and synthetic polymeric ligands have been evaluated for the functionalization of MPs [127]. Natural polymeric ligands are attractive owing to their high solubility in water and low toxicity. Common natural polymers include polymeric carbohydrate-based structures such as starch, dextran, and chitosan $[75,127]$. Notably, dextran-coated MPs showed improved intracellular labeling when used in $\mu$ NMR biosensing [128].

MPs functionalized with poly(acrylic acid) (PAA) and polyethylenimine (PEI) significantly enhanced the dispersion of MPs in water [129]. Iron oxide MPs were modified with the biocompatible polymer, poly(L-lysine), which provided a positively charged MP surface for attracting a negatively charged fluorescent agent, thus serving as a transfection agent for cancer stem cell labeling $[130,131]$. However, physical adsorption of the polymer is less robust than covalently attaching the polymeric ligands. Both chemically bound polymeric ligands and polymer shells are also well developed $[39,75,127]$.

Poly(ethylene glycol) (PEG) is widely used in biomedical applications; as a nanoparticle-modifier, it offers enhanced aqueous stability, reduction in non-specific biomolecule adsorption, and increased biocompatibility due to low toxicity $[118,132,133]$. PEG ligands can be designed as monomeric ligands, co-polymers with versatile functionality, or as a polymeric shell [115,133-136]. The one-step of synthesis of PEG-coated MPs was reported by Lutz and co-workers, which involved the copolymer poly(oligo(ethylene glycol) methacrylate-co-methacrylic acid) (P(OEGMA-co-MAA)) as a stabilizer to obtain 10-25 nm PEGylated iron oxide MPs [133]. Post-synthesis polymer modification of MPs by the direct addition of polymer chains on MPs has been reported [134,135]. Monomeric PEG silane ligands can be used to functionalize MPs for long-term stability [118]. The self-assembly of poly(ethylene glycol)-gallol (PEG-gallol) and biotin-PEG(3400)-gallol mixed with methoxy-PEG(550)-gallol on $9 \mathrm{~nm}$ iron oxide MPs stabilized in aqueous solution has been demonstrated [136]. Poly(oligoethylene glycol) methyl ether acrylate and poly(dimethyl-aminoethyl acrylate) were coated on $8 \mathrm{~nm}$ iron oxide for protein anti-fouling and siRNA delivery [121].

In addition to PEG and natural polymeric ligands, many biocompatible and functional polymers have been customized for use as ligands on MPs. Emulsion polymerization is a common method for attaching polymers to MPs [99,102,137]. Hollow mesoporous silica MPs were prepared by growing poly(tert-butyl acrylate) (PTBA) chains on MPs via seed emulsion polymerization; these MPs were used as MRI contrast agents with drug-loading capacity [102]. In another example, poly(methacrylic acid) (PMAA)-coated $8 \mathrm{~nm}$ maghemite MPs were prepared through emulsion polymerization using potassium persulfate $\left(\mathrm{K}_{2} \mathrm{~S}_{2} \mathrm{O}_{8}\right)$ as the initiator [137]. Poly(methyl methacrylate) (PMMA)-coated $\mathrm{Fe}_{3} \mathrm{O}_{4}$ MPs also can be prepared through radical polymerization via the reaction between 3-methacryloxypropyltrimethoxysilane (MPS)-functionalized MPs, methyl methacrylate (MMA), and sodium lauryl benzenesulfate as the initiator [138]. The polysilane, poly(ethylene oxide)-block-poly( $\gamma$-methacryloxypropyl-trimethoxysilane) (PEO- $b$-P $\gamma \mathrm{MPS}$ ) can be directly added 
to MPs by silanization [139]. The self-polymerized polydopamine was functionalized on iron oxide MPs, which were used as theranostic agents for mRNA detection and image-guided photothermal therapy [140].

MPs with thick polymeric shells have been commonly prepared through distillation precipitation polymerization, which includes the initiation of polymerization from the monomer with oligomer radicals, and those oligomers crosslink to grow and precipitate from solution to form a shell [141]. Many different types of polymeric shells have been prepared with this approach, including polyacrylic acid (PAA), poly(methacrylic acid) (PMAA), poly( $N, N$-methylene-bisacrylamide) (PMBBAm), and poly $\left(N, N^{\prime}\right.$-methylenebisacrylamide-co-glycidyl methacrylate) (PMG). These polymeric shells were designed for various purposes such as biomolecular adsorption, drug loading, and delivery control [142-145]. For example, PAA-coated MPs were designed to be $\mathrm{pH}$-dependent to effect controlled drug delivery [142] and to conjugate with benzoboroxole ligands for high glycoprotein capacity and low non-specific adsorption [144]. $\mathrm{Fe}_{3} \mathrm{O}_{4}$ MPs coated with PMG have proven useful in the highly specific separation of histidine-rich proteins [145].

\subsection{Biomolecular Conjugation}

The final step in the design of MPs for biomedical/biological applications is the conjugation of the functionalized MPs with biomolecules. The targeted biomolecules include small biomolecules, such as vitamins, peptides, and aptamers, as well as larger biomolecules such as DNA and proteins [146]. The functional group on the MP surface serves as a linker to bind with complementary biomolecules. For nucleic acid attachment, non-chemical methods (e.g., electrostatic interaction) and chemical methods (e.g., covalent bonding) are two primary means of bioconjugation. It is common to modify the nucleic acid chains with functional groups, such as thiols or amines, for facile attachment on MPs or sensor surfaces [45]. For larger biomolecules, such as proteins, their specific binding interaction with a wide range of subtracts and synthetic analogues are often employed. Proteins with specific receptor-substrate recognition, such as antigen-antibody and biotin-avidin interactions, are reliable tools in sensing applications $[114,116,136,147]$. A specific pair of proteins can either be used to immobilize species on MPs or on sensor surfaces to constitute the desired functionality for immunoassays or targeting studies.

Physical interactions include electrostatic, hydrophilic-hydrophobic, and affinity interactions. The primary advantage of the physical interaction method is its high efficiency without complex modification steps [7]. Several groups have demonstrated that the surface charges arising from modification with polymers (e.g., polyethylenimine, PEI) or custom ligands can be used to interact with oppositely charged biomolecules, such as positively charged MPs binding with negatively charged DNA $[148,149]$.

The most popular affinity-based attachment method is undoubtedly the strong and specific biotin-avidin interaction. The binding of biotinylated molecules with avidin moieties is highly effective in a variety of bioconjugation systems. A wide variety of biotinylated and avidin-functionalized ligands and biomolecules are commercially available or can be prepared using unspectacular methods. Moreover, biotin molecules and tetrameric streptavidin have site-specific attraction with low nonspecific binding for controlling the direction of interacted biomolecules, such as the exposure of the Fab region of an antibody toward its antigen [146].

Strategies of covalent conjugation have been studied and developed over many years. Table 2 lists six strategies commonly used for covalent bioconjugation. Weissleder et al. functionalized fluorescent MPs with amino groups and linked to them different types of small molecules, such as anhydrides, carboxylates, and thiol-terminated molecules. This functionalized nanoparticle library demonstrated the ability to modulate nanomaterial surfaces for the purpose of differentiating cell lines [150]. Li and co-workers grafted MPs with six different ligands, including amines, aldehydes, carboxylates, epoxys, mercaptos, and maleimides to immobilize proteases and evaluate their stability, enzyme activity, and reusability [114]. 
Table 2. Common Bioconjugation Strategies.

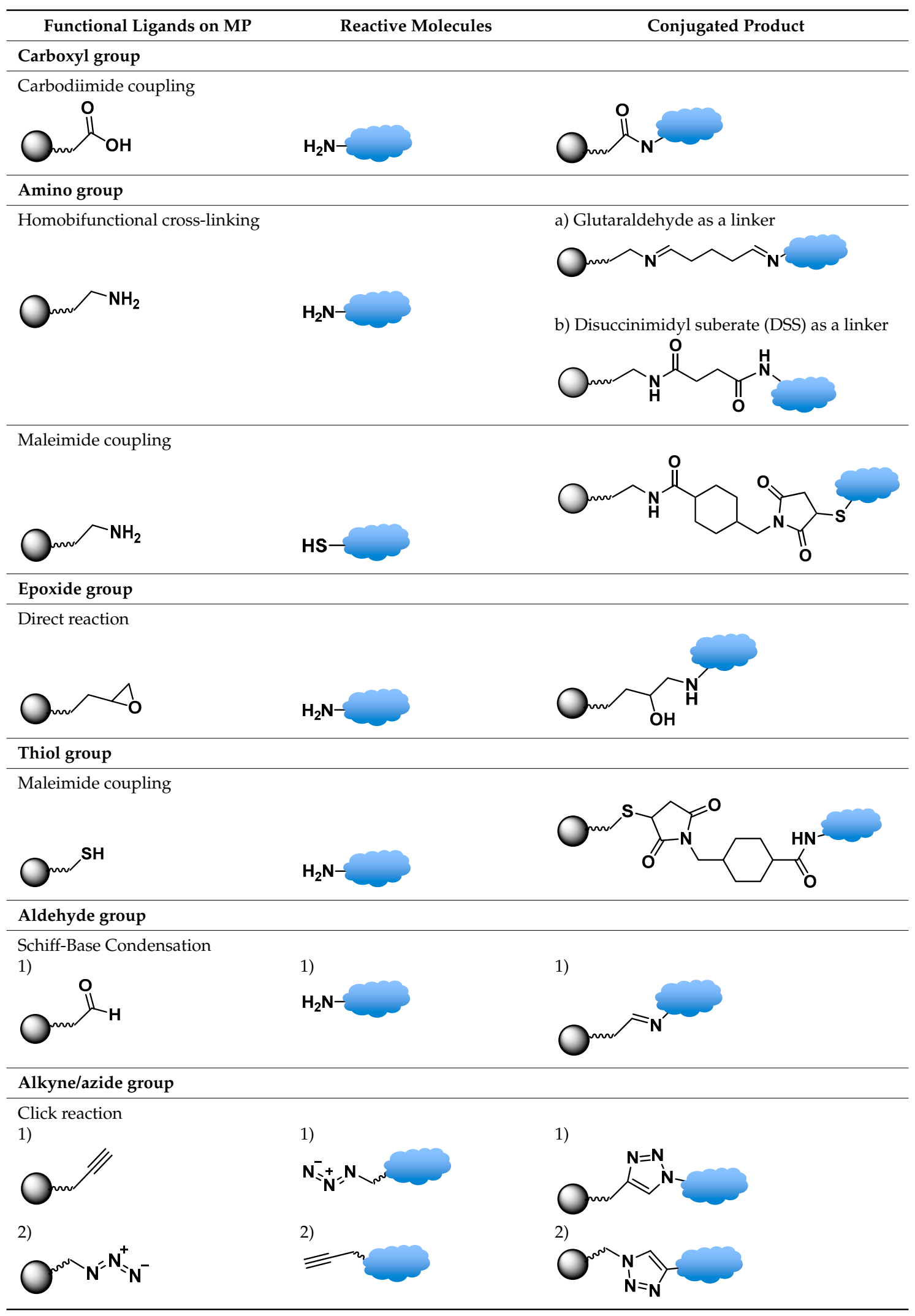

Among the various versatile routes, bio-conjugation performed through the use of homobifunctional/heterobifunctional cross-linkers, carbodiimide coupling, maleimide coupling, 
and click reactions are well-established and offer high stability in biological systems. In the case of homobifunctional cross-linkers, glutaraldehyde and discuccinimidyl suberate (DSS) have been employed as a bridge to crosslink with amine-functionalized MPs and amine-containing biomolecules [48,147].

Carbodiimide coupling is based on the formation of an amide bond directly between a carboxylate-terminated group and an amino-functionalized molecule. In general, the carboxylate-terminated ligand is attached to the MP surface, and the free amine originates from a biological species, such as a protein. The advantages of carbodiimide coupling are the mild reaction conditions (in water at room temperature) and the fact that it leads to formation of a covalent amide bond without markedly increasing the hydrodynamic radius [127]. The most common coupling reagent is 1-ethyl-3-(dimethylaminopropyl)carbodiimide hydrochloride (EDC). The addition of N-hydroxysuccinimide (NHS) or sulfo-NHS increases the efficiency via formation of the transient succinimide ester. Reports of the conjugation of MPs with proteins or fluorescent dyes via carbodiimide coupling are ubiquitous in the literature $[46,144]$.

Maleimide coupling offers a linking agent to conjugate primary amines to thiols. One approach uses amino-modified MPs to conjugate thiol-containing biomolecules, such as cysteine or herceptin. The most commonly used maleimide coupling reagent is sulfosuccinimidyl-4-(maleimidomethyl)cyclohexane-1-carboxylate (Sulfo-SMCC), which is used to activate the amino group on the MPs [114]. Another approach is the use of maleimide-modified biomolecules to crosslink with thiol-exposed ligands on the MPs. For example, the thiol group of $10 \mathrm{~nm}$ iron oxide MPs functionalized with ( $\gamma$-methacryloxypropyltrimethoxysilane, MPTES) was conjugated with maleimide-modified streptavidin for secondary binding with biotinylated anti-HER2 [114,116].

The click reaction is a bio-orthogonal reaction that is highly selective for certain functional groups and unreactive toward functional groups commonly found in biological systems [3,120,134]. A widely used route is the $\mathrm{Cu}(\mathrm{I})$-catalyzed alkyne-azide cycloaddition reaction, also known as click reaction $\mathrm{CuAAC}$. This reaction involves the coupling of an alkyne to an azide giving a 1,2,2-triazole ring, which forms a strong covalent bond between the particle surface and the biofunctional moiety. The rapid and high-yield click reaction proceeds with high specificity between the azide and alkyne functional groups, and the resulting covalent bond is stable to harsh biological media [127]. Other types of click reactions include the Diels-Alder reaction, which in one particular case [123] involves an orthogonal clickable phosphonic acid ligand designed as two clickable parts: [3+2] CuAAC reaction and [4+2] Diels-Alder reaction. The multifunctional ligand in this example is biocompatible, has good water dispersability, and conjugates with the drug of choice attached to the thermoreversible dienophile ligand [123].

\section{Detection Techniques and Their Applications}

Once the MPs are conjugated to biomolecules as a biomarker, the final step involves the detection of the MPs. In recent years, sensing in biological and biomedical applications has been gaining significant attention and development. A broad range of magnetic detection techniques has been employed for measuring the magnetic response of the MPs. For each technique, there might be more than one magnetic parameter that can be measured. For example, SQUID magnetometers are capable of measuring relaxation, remanence, and susceptibility. To avoid substantial overlap, we categorize this section based on the different physical principles of the detection techniques instead of using both the technical basis and the magnetic parameters. Within each category, the multiple detection modes will be discussed if available.

\subsection{Spintronic Sensors: Giant Magnetoresistance (GMR), Tunneling Magnetoresistance (TMR), Planar Hall Effect (PHE)}

Spintronic devices and their biosensing applications have been explored for decades. From this research, three types of magnetic detection techniques have emerged: giant magnetoresistance (GMR) 
sensors, tunneling magnetoresistance (TMR) sensors, and planar Hall effect (PHE) sensors [12,15,16,20]. Correspondingly, a wide variety of biosensing applications have been demonstrated.

Since its discovery in the 1980s, the GMR effect has been largely used in data recording [150]. More recently, GMR has found use as a magnetoresistance-based, solid-state magnetic sensor. Among the different types of sensing methods, the spin valve provides higher sensitivity with a micron-sized design [151-153]. A spin-valve GMR sensor consists of an artificial magnetic structure with alternating ferromagnetic and nonmagnetic layers. The magnetoresistance effect is caused by the spin-orbital coupling between conduction electrons crossing the different layers. The variation in magnetoresistance provides quantitative analysis by this spin-dependent sensor [3,6,154,155].

GMR sensors can be used for immunoassays in a manner related to enzyme-linked immunosorbent assays (ELISA). Like the sandwich-type approach in ELISA, sample preparation includes the immobilization of a molecular target on the sensor surface and the addition of tagged magnetic probes $[156,157]$. When the ligand-tagged MPs interact with the receptors bound to the sensor, the external magnetic dipole field from the magnetic label causes the magnetoresistance to change. The GMR sensor then detects this small magnetic signal [84].

The magnetic labels are usually fabricated as MPs. In early studies, micron-sized MPs $(1-3 \mu \mathrm{m})$ were commonly employed as the magnetic labels [84]. However, their bulky size caused them to diffuse slowly and increased the distance of the magnetic labels from the sensor surface, inhibiting both the assay speed and detection sensitivity. Recent developments using nanometer-sized MPs as probes overcame these limitations of slow diffusion and label-sensor remoteness, which has enabled the sensitive detection of low target concentrations [158-160]. The smaller magnetic labels increased the density of labels bound across the sensor surface and improved the sensitivity of the sensor. For example, Xing and co-workers used high magnetic moment, cubic $12.8 \mathrm{~nm}$ FeCo MPs to quantify interleukin-6 (IL-6) from unprocessed human sera [160]. On the other hand, although quantification of single particles can be well defined, the size uniformity and the natural preference toward aggregation pose a challenge [158].

Importantly, magnetoresistance sensors are promising as low-cost alternatives to biochip-based biosensors [161]. Two major uses of GMR sensors include studies of DNA-DNA interactions and protein immune-sensing in which either DNAs or antibodies are used as probes to detect DNAs or proteins immobilized on the sensor surface. Current applications focus on the detection of specific DNA sequences and the improvement in detection sensitivity compared to traditional optical immunoassays [151].

GMR sensors offer significant advantages for multiplexed detection. An early GMR biosensor was developed as a bead array counter (BARC) system [162]. The integration of micron-sized MPs $(2.8 \mu \mathrm{m})$ with the magnetoresistance sensor was able to detect biomolecular interactions such DNA-DNA hybridization [162,163]. Lately, submicron-sized magnetic markers (350 $\mathrm{nm}$ and $860 \mathrm{~nm}$ ) have been used to detect DNA at concentrations ranging from $10 \mathrm{ng} / \mu \mathrm{L}$ to $16 \mathrm{pg} / \mu \mathrm{L}$ [164]. Spin-valve type GMR sensors have become popular as biochips due to their better linearity for quantification $[20,153]$. Fine-tuning the architectures of sensor arrays has been reported to improve the detection limit; one approach is to adjust the dimensions of sensor array for the detection of individual MPs [152]. Another approach is to use synthetic antiferromagnetic particles, which are typically fabricated as double layers of $\mathrm{Co}_{90} \mathrm{Fe}_{10}$ separated by a nonmagnetic spacer layer of Ru with almost zero magnetic remanence and high magnetic moment. With this approach, Fu et al. synthesized streptavidin-functionalized $100 \mathrm{~nm}$ synthetic antiferromagnetic nanoparticles to detect biotin-labeled DNA at a high sensitivity of $10 \mathrm{pM}$ [165]. The hybrid spin-valve GMR sensor provided massive parallel sensing with a 256-sensor pre-chip array in $0.18 \mu \mathrm{m}$ complementary metal-oxide-semiconductor (CMOS). This biosensor design monitored real-time kinetics in a protein array and detected ovarian cancer biomarkers as low as $10 \mathrm{fM}$ [155]. By varying the architecture, a 64-sensor array as the circuit architecture afforded shorter readout times with a detection limit reaching $5 \mathrm{fM}$ of protein [166]. 
In an advanced GMR biochip designed to study DNA-DNA interactions rather than DNA probe-target detection, an on-chip GMR sensor offers real-time measurement of DNA binding and thermal denaturation on the solid-surface hybridization with temperature control [167]. Another study reported the detection of cell-free DNA (cf-DNA) fragments using an array of 30 spin-valve GMRs integrated on a portable biochip platform for cancer diagnostics [168]. Through surface modification of a GMR sensor with amino-terminated $\mathrm{SiO}_{2}$, the sensor was capable of detecting different bio-targets, such as amine-modified DNA and interlukin-6 (IL-6) antibodies using a 30-nm magnetic marker [169].

Immunosensors and protein-based sensors based on the principle of GMR have also been developed. A dose-response detection of the biomarker $S 100 \beta$ with a detection limit as low as $27 \mathrm{pg} / \mathrm{mL}$ was prepared by increasing the active area using $300 \mathrm{~nm}$ magnetic nanoparticles and controlling the surface chemistry of the sensor [159]. Multiplex protein assays were reported to sense eight types of cancer-related cytokines in real time. The magnetic signal was amplified, and the detection concentration extended to the $\mathrm{fM}$ range by using $50 \mathrm{~nm}$ magnetic labels [158].

As shown in Figure 5, a protein-based GMR sensor was further developed to quantify and monitor protein interactions and detect multiplexed proteins by functionalization with at least four different antibodies. The dynamic range can cover six orders of magnitude with a detection limit is as low as $50 \mathrm{aM}$ [12]. A competition-based GMR assay was developed to detect unprocessed urine using smaller $(12.8 \mathrm{~nm})$ FeCo MPs [170]. Additionally, by combining a GMR sensor with magnetic tweezers, real-time DNA stretching and DNA-enzyme interactions were monitored [171]. The versatile applications of GMR sensors are summarized in Table 3.

a)

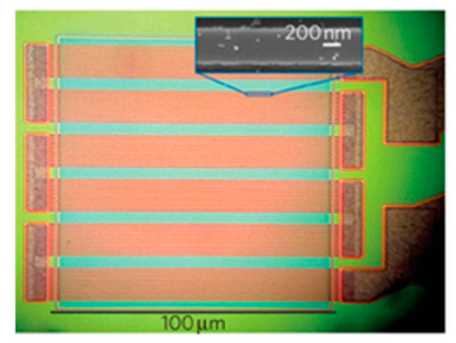

c)

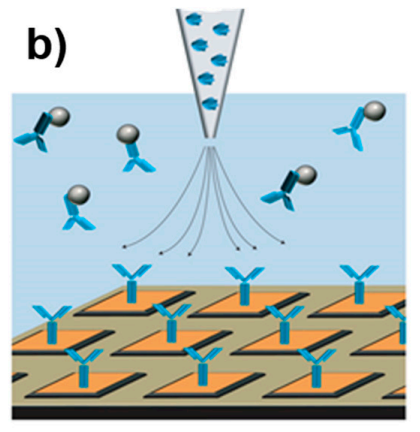

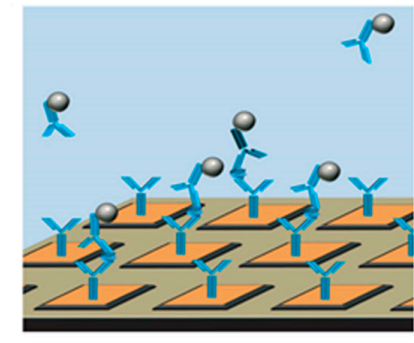

d)

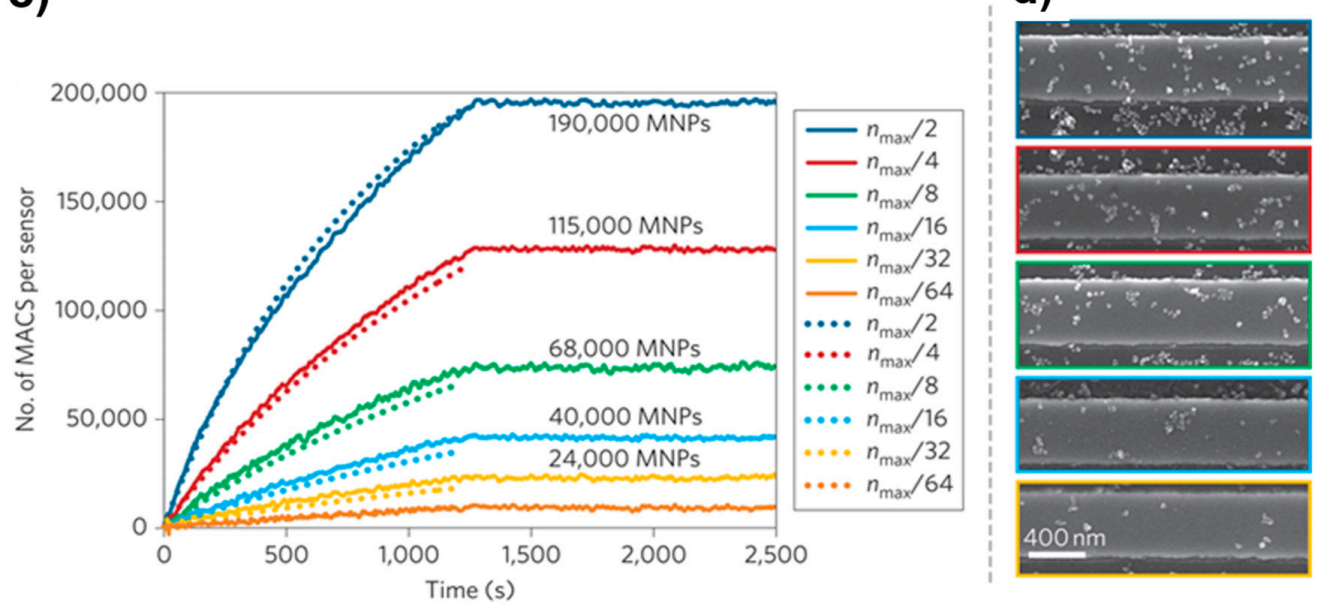

Figure 5. GMR applications: (a) optical image of GMR sensor architecture, where the upper right inset shows the SEM image of one strip with several bound MPs, (b) illustration showing the magnetic particle detection process, (c) real-time binding curve with fitting, and (d) SEM image of a section of the GMR sensor. Reproduced with permission from [12], copyright 2011 Nature Publishing Group. 
TMR sensors are based on the tunnel magnetoresistance of a magnetic tunnel junction, which consists of a sandwich of two magnetic layers separated by an insulating layer (commonly $\mathrm{MgO}$ ). TMR sensors offer a higher magnetoresistance ratio compared to GMR sensors and might provide higher sensitivity at low magnetic fields [15]. TMR sensors have been used for the detection of DNA hybridization and avidin binding in conjunction with $12 \mathrm{~nm} \mathrm{MnFe}{ }_{2} \mathrm{O}_{4} \mathrm{MPs}$ [172]. Separately, an arrayed TMR sensor has been designed to detect target DNA by using $16 \mathrm{~nm} \mathrm{Fe}_{3} \mathrm{O}_{4}$ and 50-nm polymer coated MPs [15]. Immunoassays with TMR sensors have been successfully developed to detect the liver cancer biomarker, $\alpha$-fetoprotein (AFP) [173]. Meanwhile, the Hutter group has developed nanoscale TMR sensors to study the influence of the location of $1 \mu \mathrm{m}$ MPs on the sensor surface for single-particle detection [174]. TMR sensors have been used to detect small quantities of iron oxide MPs in the complex lymphatic environment with good spatial resolution [175]. Additionally, a portable system has been integrated with a microfluidic apparatus as a lab-on-a-chip platform to detect pathogenic DNA below nM range sensitivity [176].

Planar Hall effect (PHE) sensors have been used to detect micro- and nano-sized MPs in biosensing [177]. The planar Hall effect is an exchange-biased permalloy planar sensor based on the anisotropic magnetoresistance effect of ferromagnetic materials. PHE sensors are capable of detecting micron-sized streptavidin-functionalized MPs [16]. A study of exchange-biased PHE sensors was investigated between $-10{ }^{\circ} \mathrm{C}$ and $70{ }^{\circ} \mathrm{C}$ for temperature stability in biosensing experiments [178]. Miniaturized PHE sensors have been integrated with microfluidic systems and developed as room-temperature magnetorelaxometers to detect dynamic Brownian relaxation $[179,180]$. Recently, various PHE sensor architectures have been reported such as the spin-valve PHE with single-particle detection $[181,182]$ and a PHE bridge sensor $[183,184]$. The latter gave higher signal compared to the cross geometry PHE sensor and has been used for on-chip DNA detection by measuring the Brownian relaxation of MPs [183].

\subsection{Nuclear Magnetic Resonance (NMR)}

Nuclear magnetic resonance (NMR) is a powerful magnetic phenomenon that can be used to identify, image, and detect molecules. In contrast to a surface-based sensor such as GMR, NMR and SQUID (described in the next section) are capable of measuring an entire volume of the sample $[3,6,156]$. NMR for detecting MPs is based on the change in nuclear spin relaxation induced by the magnetic field of MPs: the higher the transverse relaxation rate $\left(R_{2}\right)$, the higher the concentration of MPs.

One of the most promising applications of NMR in MP-based biosensing is magnetic resonance imaging (MRI) of localized MP-labeled molecules. The use of MPs in MRI is a non-invasive clinical method of molecular-level imaging. MPs play a dual role of both specific tags and contrast agents. The best known and commercially available MP-based contrast agents contain paramagnetic or superparamagnetic materials (e.g., manganese-based Mn-DPDP and magnetite-based Lumirem, respectively). Several reviews detail the design and functionality of MPs in MRI imaging with applications ranging from the molecular/cellular level to the organ level $[7,8,37-39,74]$. 
Table 3. MPs Detected by Various Magnetometer-Based Biosensing Techniques.

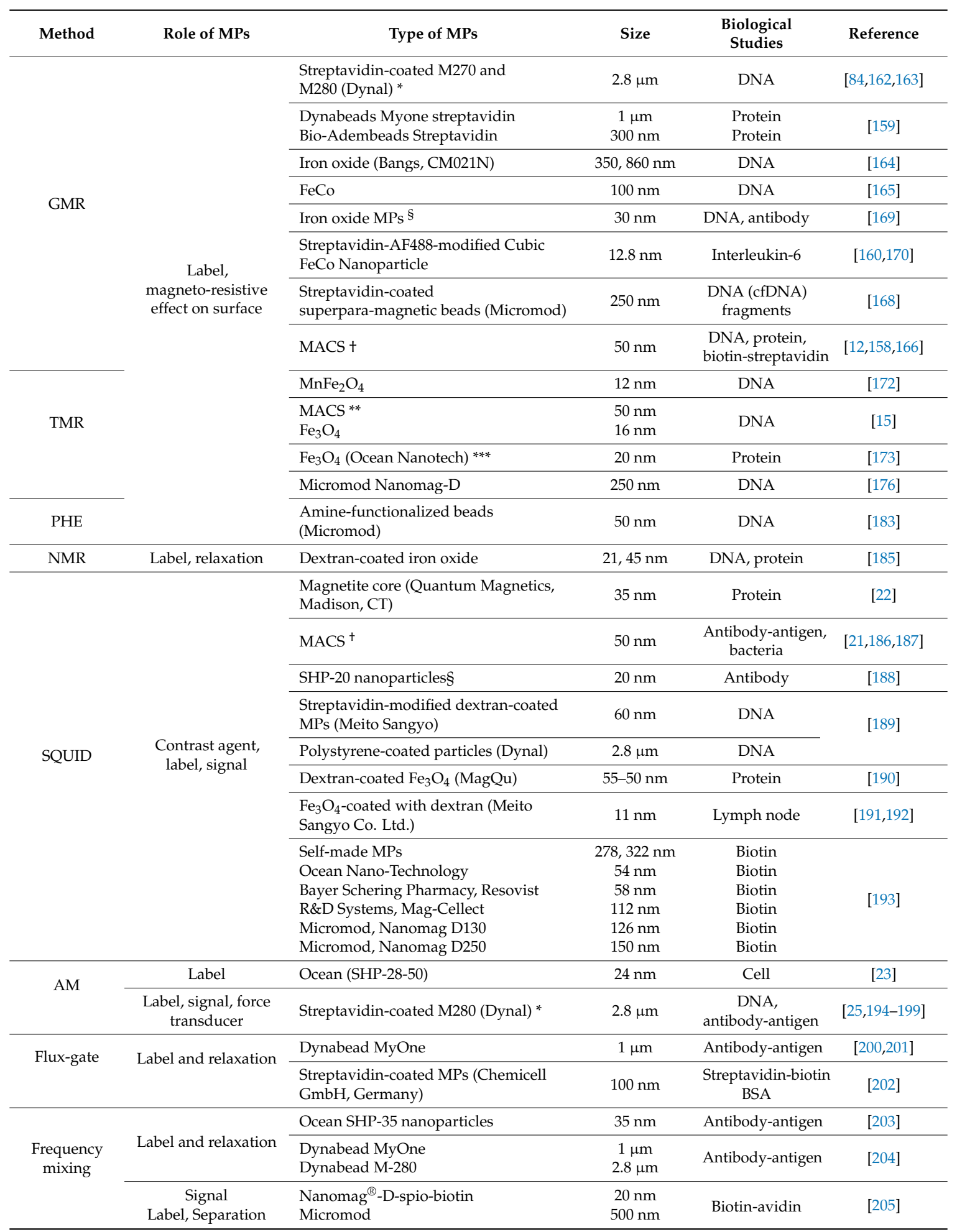

* M270 and M280 (Dynal): 17-20\% of iron oxide in a polymer-based microsphere. § Ocean nanoparticles (Ocean Nanotech; Springdale, AR, USA): single-core magnetite particles coated with a thin ( $\sim-4 \mathrm{~nm}$ thick) layer of polymer and functionalized with carboxyl groups to enable conjugation to antibodies, with composite diameters $\sim 20-30 \mathrm{~nm}$.

${ }^{+}$MACS (Miltenyi Biotec, Germany): $55-59 \% \mathrm{Fe}_{2} \mathrm{O}_{3}+35-39 \%$ dextran $+2-10 \%$ biomolecular.

The multimodal labeling of MPs can overcome several limitations of single-purpose use found with optical bleaching and/or spatial resolution in optical imaging [161]. For example, multifunctional magnetofluorescent MPs in trimodal imaging combine MRI (iron oxide core), positron 
emission tomography (PET) sensing (chelator-ligand complexing the radiotracer $\mathrm{Cu}$ ), and fluorescence (VivoTag-680) [206]. Moreover, MPs can play many functional roles, such as MRI contrast agents, radionuclide tracers, targeting moieties, and optical tags (e.g., fluorescence dyes, quantum dots, and NIR absorbers) [82,207].

The NMR principle has also been widely used in magnetic relaxation switches and MP-based relaxation sensors. The magnetic relaxation nanoswitches (Figure 6a) proposed by the Weissleder group are based on the self-assembly of 3-5 $\mathrm{nm}$ MPs to analyze molecules and cause a change in the spin-spin relaxation times of neighboring water molecules. The change in $\mathrm{T}_{2}$ relaxation is detected by a benchtop NMR relaxometer and can be employed to detect varieties of biomolecules such as DNAs, proteins, and enzymes [40,208].

With the improvement in electronics brought about by using integrated circuit (IC) chips and micrometer-sized detection coils, it is now possible to have portable and miniaturized NMR devices. The miniaturized NMR ( $\mu$ NMR) provides highly sensitive point-of-care diagnostics and can be integrated with microfluidic systems $[209,210]$. Application of $\mu$ NMR in magnetic relaxation switches has advanced from molecular sensing to clinical diagnosis. Molecular sensing includes whole cells, proteins, DNA/mRNA, metabolites, drugs, viruses, and bacteria [211-213]. For example, Figure 6b,c illustrates a $\mu$ NMR-based magneto-DNA assay that was used for the detection and phenotyping of bacteria [13]. In clinical studies, $\mu$ NMR was successfully used to quantify and characterize lung tumor cells in primary blood samples and to monitor glioblastoma therapy from the blood samples of patients [208,212,214].

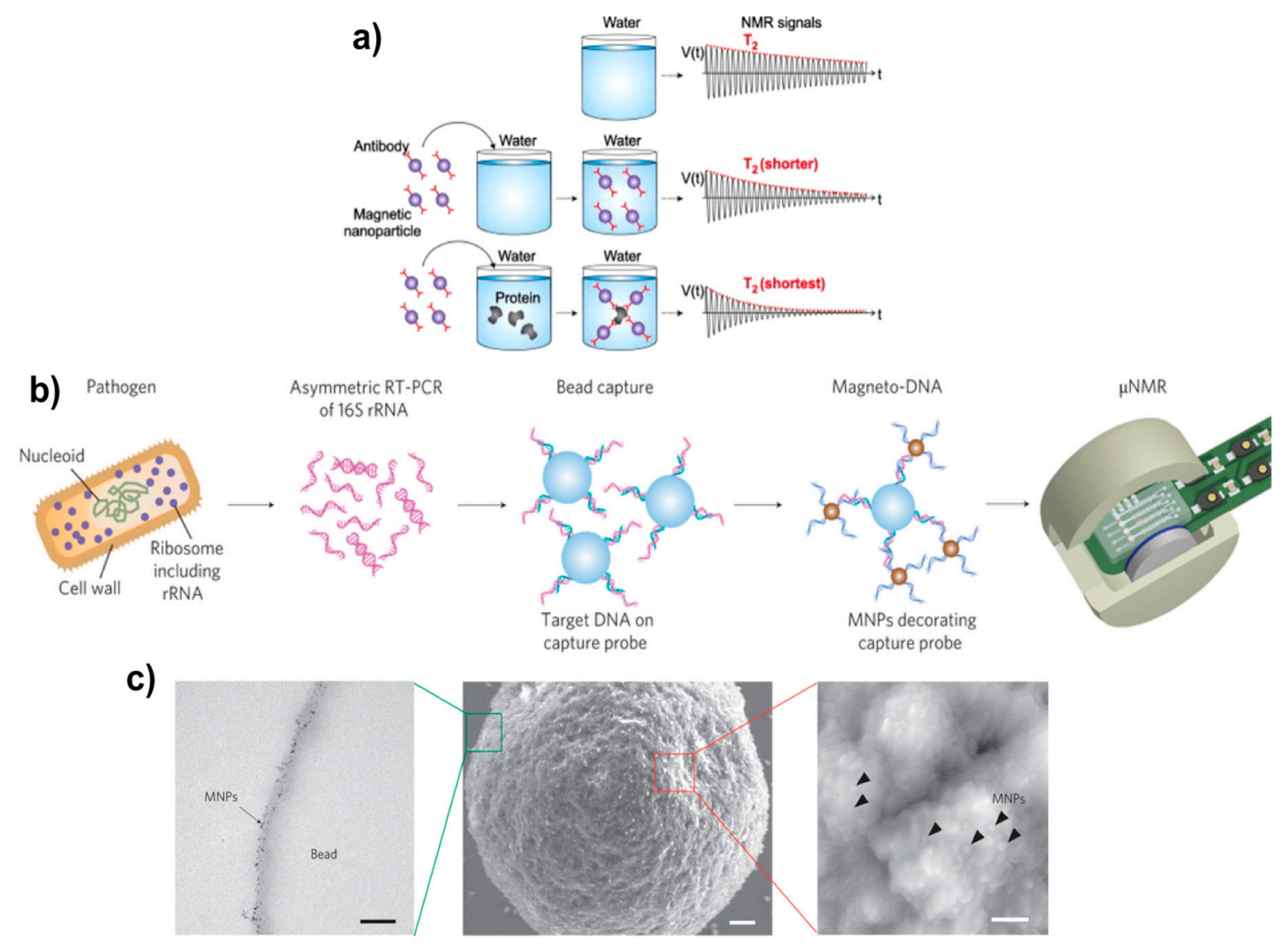

Figure 6. (a) Relaxation biosensor in NMR. (b) The magnetic switch application in magneto-DNA assay. (c) Capture bead and MP probe under TEM (left, scale bar, $100 \mathrm{~nm}$ ), SEM (middle, scale bar $300 \mathrm{~nm}$ ), and AFM (right, scale bar $100 \mathrm{~nm}$ ). Reproduced with permission from [210], copyright 2014 American Chemical Society, and [40], copyright 2013 Nature Publishing Group. 


\subsection{Superconducting Quantum Interference Device (SQUID)}

SQUID has long been recognized as the most sensitive magnetometer, especially for low frequency applications [215,216]. The device is based on superconducting loops containing Josephson junctions. The current induced in the SQUID ring by an external magnetic flux gives rise to a change in voltage across the junction, which generates an output signal from the amplified voltage. SQUID-based biosensors are classified as relaxation-type, remanence-type, and susceptibility-type sensors [217]. In early studies, SQUID was used to detect ferromagnetic contamination in the lungs and other organs in the human body [218].

Most MP-based detection methods are based on measuring the change in magnetic field produced by the MPs. In the case of the relaxation sensor, bound MPs relax (Néel relaxation time of $\sim 1 \mathrm{~s}$ for $\gamma-\mathrm{Fe}_{2} \mathrm{O}_{3}$ particles with $10 \mathrm{~nm}$ diameters) at a slower pace than unbound MPs (Brownian relaxation of $\sim 50 \mu \mathrm{s}$ for particles with $50 \mathrm{~nm}$ hydrodynamic diameter) [22]. Immunoassays based on Néel relaxation use direct current (DC) SQUID. For example, the Clarke group used a magnetic gradiometer-improved SQUID sensor to detect FLAG-tagged liposomes via immunoassay [22,219]. Figure 7 illustrates the use of SQUID to detect a magnetically-labeled Listeria monocytogenes bacteria suspension and to measure the binding rate between iron oxide MPs and the bacteria [186]. Another in vitro study explored the detection of iron oxide MPs conjugated to Her2-expressing MCF/Her2-18 cells (breast cancer cells) and the quantification of iron in tumors and the liver by SQUID-detected magnetic relaxometry [188]. A surface-based biosensor with high- $\mathrm{T}_{\mathrm{c}}$ SQUID has also been used to measure the interaction of MP-labeled DNAs and antibodies with surface-immobilized receptors $[187,192]$. Immunoassays using SQUID can be studied by recording the magnetic response after switching off the magnetic field [220]. This type of magnetorelaxometry platform also allows kinetic studies of antibody-antigen reactions in whole blood samples [221]. Relevant liquid-phase immunoassays use the Brownian relaxation of labeled MPs to detect biotin and distinguish between bound and unbound MPs without requiring a washing step [193].

a)

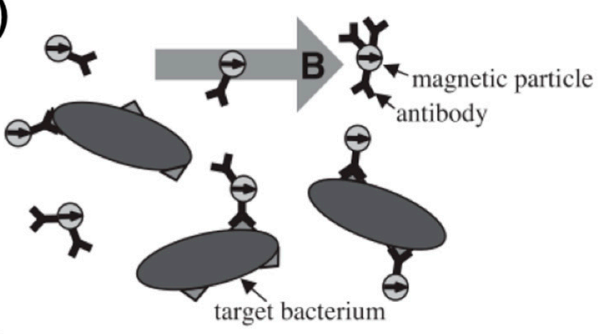

b)

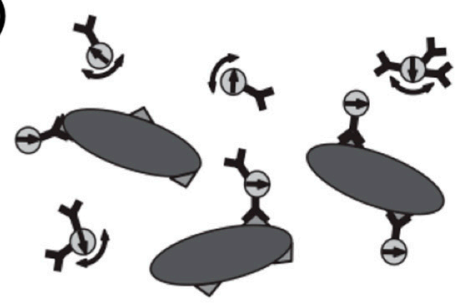

c)

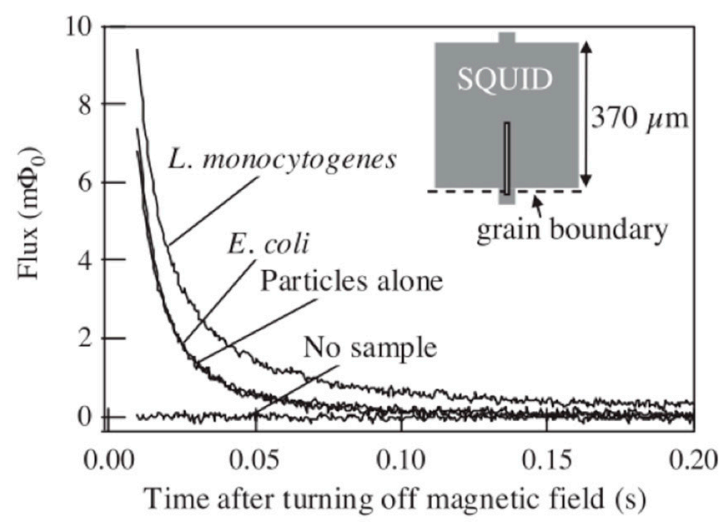

Figure 7. An example application of SQUID: (a) an applied magnetic field aligns the magnetic moment of MPs conjugated with an antibody, which are added into a bacteria-laden liquid suspension, (b) after removing the magnetic field, the unbound MPs have randomized magnetic moments due to Brownian rotation while the bound MPs slowly relax by Néel relaxation, and (c) magnetic decay signals including bacteria and unbound MPs. Insert: configuration of the YBCO SQUID. Reproduced with permission from [186], copyright 2004 National Academy of Sciences, U.S.A.

Remanence biosensors were also used to measure bound MPs in the absence of an external field after MPs were exposed to a magnetic field. The unbound MPs were removed as a ferrofluid [24]. Various reports in the literature measured MPs in ultra-dilute DNA solutions and multi-sample biological immunoassays with a detection limit as low as $30 \mathrm{pg}$ of $\mathrm{Fe}_{3} \mathrm{O}_{4}$ MPs [24,189,222]. A SQUID-based magnetic 
immunoassay was used to distinguish between bound and unbound IgE on a surface without requiring any prior separation process [185]. In addition, the remanence measurement by SQUID can non-invasively track and identify MPs in human organs [217]. Using susceptibility measurements, the Yang group used immunomagnetic reduction methods to detect Alzheimer's disease with a SQUID-based mixed-frequency AC magnetosusceptometer [190]. Other susceptibility measurements include the identification of in vivo ferrite MPs loaded on a tumor and $11 \mathrm{~nm}$ MPs in the lymph nodes of rats [21,191]. SQUID can also be used for MRI at ultra-low fields (mT). SQUID-based MRI in microtesla magnetic fields can image tumors with substantially greater $\mathrm{T}_{1}$-contrast as compared to high-field MRI. Through the use of MPs, the MRI can trace MP agglomerates (both bound and unbound MPs) and map magnetization decays by detecting their faster Néel relaxation in a magnetic field [223]. Liao and co-workers used high $\mathrm{T}_{\mathrm{C}}$ SQUID to image field-dependent $T_{1}$ relaxation of MPs in ferrofluids [224]. Furthermore, clinical magnetoencephalographic systems equipped with SQUID sensors can significantly enhance the measurement of neuronal currents when $25 \mathrm{~nm} \mathrm{Fe}{ }_{2} \mathrm{O}_{3}$ MPs are bound to a specific target [225].

\subsection{Atomic Magnetometer (AM)}

AM has been recently developed as a highly sensitive technique for measuring DC magnetic fields and rivals SQUID, with an advantage of no cryogenics required. The principle of AM is to measure the magneto-optical effects of spin-polarized atoms interacting with a probing laser beam in a magnetic field [226]. In AM measurements, a pump laser is typically used to polarize an alkali metal $(\mathrm{K}, \mathrm{Rb}$, or $\mathrm{Cs})$ in the vapor phase. The subsequent precession of the polarized atoms in the magnetic field is detected by the optical rotation of a probe laser, which can be the same laser as the pump laser. Several different configurations of AM have been developed [157,226-228]. The sensitivity of an AM has been reported to be as low as $0.01 \mathrm{ft} / \mathrm{Hz}^{1 / 2}$ for a spin-exchange relaxation-free magnetometer [227]. Atomic magnetometers have been used to detect MPs in a variety of settings. For example, an AM was designed to detect a single $2-\mu \mathrm{m}$ cobalt particle with continuous flow using microfabrication technology [228]. Recently, an important development centers on the scanning imaging method, which simultaneously provides spatial information and quantification of functionalized MPs; the resolution is approximately $20 \mu \mathrm{m}$ with a 1-cm detection distance [229]. The imaging of MPs has been accomplished at physiological temperature; this measurement is suitable to study biological samples using an immunoassay [230]. Moreover, AM can be developed as a magnetic relaxometer for detecting medical samples such as targeted MPs and targeted cancer cells [23].

To reveal molecular information in MP-based biosensing, a technique described as force-induced remanent magnetization spectroscopy (FIRMS) has been recently invented [25]. FIRMS, with the integration of magnetic sensing using an atomic magnetometer, has been shown to be useful for studying specific molecular interactions between target-receptor biological pairs with unprecedented precision $[25,229]$. In this application, MPs are immobilized on a surface using a desired ligand-receptor pair to be studied, such as DNA duplexes or antibody-antigen pairs. When the applied mechanical force matches the binding force, bond dissociation gives rise to unbound MPs and their subsequent Brownian motion or removal; the reduced number of bound MPs remaining on the surface leads to a detectable reduction in the magnetic signal.

The atomic magnetometer is the detector that measures the remanent magnetization from bound MPs on the surface. To distinguish between molecule-specific bindings, the applied external force on the receptor-tagged MPs is quantified. The external force is either a centrifugal force or an acoustic force as illustrated in Figure 8 [25,194]. Implementation of mechanical force in magnetic detection provides direct biological information on the binding strength of ligand-receptor pairs and can be used to investigate the precise interactions among biomolecules [25,30]. In FIRMS, MPs play three different functional roles: biological markers, magnetic signal carriers, and force transducers.

The FIRMS technique has been used to study the binding force of the mouse IgG antigen-antibody interaction and DNA pairs as shown in Figure 8a-c $[195,196]$. In addition, the FIRMS technique provides information on the sequence and chiral selectivity of drug-DNA interactions [231]. A recent 
study using FIRMS was able to distinguish the human CD4 antibody-antigen binding force on antigen-functionalized surfaces and on CD4+ T-cell surfaces [197]. In another study, the FIRMS technique used the DNA binding force as a reference force to probe ribosome translocation with motor protein EF-G [198]. A FIRMS-derived technique, exchange-induced remanent magnetization (EXIRM), is based on the competitive binding between target microRNA and magnetically-labeled defect RNA and can be used for the label-free detection of microRNA. The exchanged microRNA can be detected and quantified through magnetic signal imaging even at a concentration as low as $10^{4}$ molecules [199].
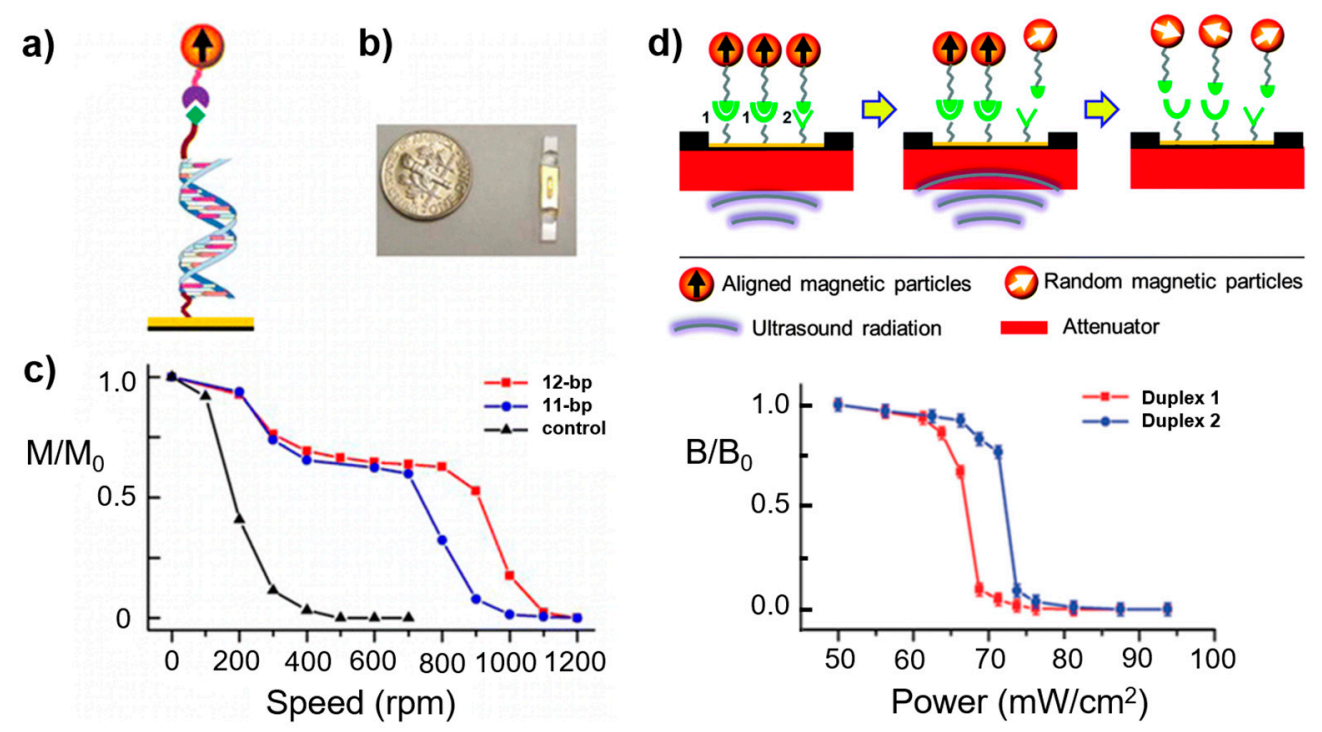

Figure 8. FIRMS studies using DNA: (a) a schematic of the FIRMS setup for DNA duplexes, (b) a photo of the sample well, (c) two DNA duplexes distinguished in a plot of magnetization versus force, and (d) the principle of acoustic radiation force (top figure) and an illustration binding profile of two DNA duplexes with the plot of magnetic field versus ultrasound power. Reproduced with permissions from [194], copyright 2014 Royal Society of Chemistry and from ref. [195], and copyright 2013 American Chemical Society.

\subsection{Fluxgate Sensor}

The fluxgate magnetometer has been commonly used to detect the change in magnetic fields for various disciplines such as archeology and oil-field surveys [29]. To detect MPs, the fluxgate sensor has been developed as a magnetorelaxometry technique [17]. Compared to a SQUID-type relaxometer, a fluxgate sensor offers room temperature detection and absolute magnetic fields [232]. The Schilling group has reported the potential of magnetic relaxation immunoassays by fluxgate magnetorelaxometry for various MP samples, including $\mathrm{Fe}_{3} \mathrm{O}_{4} \mathrm{MPs}$ with or without a functionalized shell and MPs used in the degradation of hydrogels [232-234]. Binding assays based on fluxgate magnetorelaxometry have been used to study biotinylated agarose beads and bovine serum protein with streptavidin-functionalized MPs [202]. The complex susceptibility of $\mathrm{CoFe}_{2} \mathrm{O}_{4} \mathrm{MPs}$ in gelatin solution has also been explored [235]. A micro-fluxgate-based biosensor was reported to detect carcinoembryonic antigen and $\alpha$-fetoprotein in a double-antibody sandwich assay at a detection limit of $0.1 \mu \mathrm{g} / \mathrm{mL}$ of Dynabeads MPs and detectable antigen at $1 \mathrm{pg} / \mathrm{mL}$ [200]. Furthermore, fluxgate magnetometers have also been used to characterize the magnetization and relaxation dynamics of immobilized $\mathrm{Fe}_{3} \mathrm{O}_{4}$ MPs $[236,237]$.

\subsection{Frequency Mixing Magnetic Detection Techniques}

Frequency mixing magnetic biosensors have been developed based on the detection of nonlinear magnetic materials. In this technique, magnetic fields of two different frequencies are used to excite the material, which gives a nonlinear response in which the frequency is a linear combination of the 
two separate excitation frequencies. Detection of the response indicates the presence of the magnetic material, for example, MPs $[26,204]$. This technique is specific to the applications of superparamagnetic MPs due to their nonlinear magnetic characteristics.

Applications of this technique have been demonstrated with the detection of many biological species, including c-reactive protein determination [238], Francisella tularensis in buffer and serum [239], Yersinia pestis in buffer and human blood serum [240], lipopolysaccharide from Francisella tularensis and F1 capsular antigen from Yersinia pestis [204], plant pathogens [241], and influenza A viruses on a nitrocellulose membrane platform [242]. Various types of immunoassays have been developed. For example, the Shin group reported a frequency mixing bioassay that employs two different MPs combined that work as magnetic separating and labeling in one effective analytical procedure; this study demonstrated the use of large biotinylated MPs for magnetic separation and small biotinylated MPs for magnetic quantification [205]. In another example, the planar frequency mixing magnetic technique employed 2D scanning imaging of superparamagnetic iron oxide MPs in a microfluidic platform for immunoassays. It successfully detected amyloid beta 42 (A $\beta 42)$, a promising biomarker of Alzheimer's disease [243]. Furthermore, mixing-frequency magnetic detection has been reported to provide a volume-based magnetic sensing method. This method measured the Brownian relaxation of MPs as a way of monitoring the binding kinetics between protein $G$ and its antibody [203].

\subsection{Other Techniques}

In addition to the techniques mentioned above, several alternative methods have been developed to detect magnetic particles. For example, susceptometry has been used to study the hydrodynamic size distribution of MPs using magneto-optical devices [244] and the reaction kinetics of MP clustering [245]. Magnetic binding assays were also reported to detect BSA adsorption using magnetic markers and a magnetic permeability meter [246]. Another related technique involves the air-core magnetometer, which is commonly used in biomedical applications [18]. In the inductive coil magnetic resonance detection, the effect of MP shape on signal amplification has been evaluated based on the magnetic susceptibility of oriented nanostructures [247]. Moreover, sensors based on domain wall movement have been developed to detect and localize MPs $[19,248]$.

\section{Summary and Perspectives}

Magnetic particles (MPs) have been used in a wide range of diverse applications. In biomolecular sensing and imaging, MPs play a multifunctional role, including being a molecule-specific tag, a signal provider, or even a force dragger. Therefore, high magnetic strength, stable, and multifunctional MPs need to be judiciously designed for each technique targeted; the fabrication of such tailored MPs will lead to further enhanced biosensing capabilities. To expand the functionality of MPs and tailor them to each application, the composition and selection of suitable magnetic materials, surface-functional groups, and target molecules are all critical issues. This review covered the basic procedures for the custom synthesis of MPs for a range of biological applications and described several magnetic detection techniques (e.g., spintronic sensors, SQUIDs, AM-based sensors, and NMR sensors) that currently utilize MPs in biosensing applications. From the many studies reported, it is clear that size selection is one of the important factors in the choice of MPs in different types of magnetometer techniques. MPs smaller than $100 \mathrm{~nm}$ are widely used in applications based on the volumetric types of magnetometers, such as MRI imaging and SQUID-based immunoassays, where smaller particle sizes are needed (e.g., for cell uptake). On the other hand, large MPs (>100 nm) are commonly used in surface-based techniques for the quantification of properties, such as the GMR sensor and the FIRMS technique, where the larger particle give measurements with enhanced signal-to-noise ratios. 
Acknowledgments: We thank the Asian Office of Aerospace Research and Development (AFOSR/AOARD FA2386-16-1-4067), the Robert A. Welch Foundation (E-1320), the National Science Foundation (ECCS-1508845), and the Texas Center for Superconductivity for supporting this research.

Conflicts of Interest: The authors declare no conflict of interest.

\section{References}

1. Krishnan, K.M. Biomedical nanomagnetics: A spin through possibilities in imaging, diagnostics, and therapy. IEEE Trans. Magn. 2010, 46, 2523-2558. [CrossRef] [PubMed]

2. Colombo, M.; Carregal-Romero, S.; Casula, M.F.; Gutierrez, L.; Morales, M.P.; Bohm, I.B.; Heverhagen, J.T.; Prosperi, D.; Parak, W.J. Biological applications of magnetic nanoparticles. Chem. Soc. Rev. 2012, 41, 4306-4334. [CrossRef] [PubMed]

3. Lee, H.; Shin, T.-H.; Cheon, J.; Weissleder, R. Recent developments in magnetic diagnostic systems. Chem. Rev. 2015, 115, 10690-10724. [CrossRef] [PubMed]

4. Yoo, D.; Lee, J.-H.; Shin, T.-H.; Cheon, J. Theranostic magnetic nanoparticles. Acc. Chem. Res. 2011, 44, 863-874. [CrossRef] [PubMed]

5. Zhao, F.; Zhao, Y.; Liu, Y.; Chang, X.; Chen, C.; Zhao, Y. Cellular uptake, intracellular trafficking, and cytotoxicity of nanomaterials. Small 2011, 7, 1322-1337. [CrossRef] [PubMed]

6. Issadore, D.; Park, Y.I.; Shao, H.; Min, C.; Lee, K.; Liong, M.; Weissleder, R.; Lee, H. Magnetic sensing technology for molecular analyses. Lab Chip 2014, 14, 2385-2397. [CrossRef] [PubMed]

7. Veiseh, O.; Gunn, J.W.; Zhang, M. Design and fabrication of magnetic nanoparticles for targeted drug delivery and imaging. Adv. Drug Deliv. Rev. 2010, 62, 284-304. [CrossRef] [PubMed]

8. Frey, N.A.; Peng, S.; Cheng, K.; Sun, S. Magnetic nanoparticles: Synthesis, functionalization, and applications in bioimaging and magnetic energy storage. Chem. Soc. Rev. 2009, 38, 2532-2542. [CrossRef] [PubMed]

9. Gillis, P.; Koenig, S.H. Transverse relaxation of solvent protons induced by magnetized spheres: Application to ferritin, erythrocytes, and magnetite. Magn. Reson. Med. 1987, 5, 323-345. [CrossRef] [PubMed]

10. McGuinness, L.P.; Yan, Y.; Stacey, A.; Simpson, D.A.; Hall, L.T.; Maclaurin, D.; Prawer, S.; Mulvaney, P.; Wrachtrup, J.; Caruso, F.; et al. Quantum measurement and orientation tracking of fluorescent nanodiamonds inside living cells. Nat. Nanotechnol. 2011, 6, 358-363. [CrossRef] [PubMed]

11. Coey, J.M.D. Magnetism and Magnetic Materials; Cambridge University Press: Cambridge, UK, $2010 ;$ p. 614.

12. Gaster, R.S.; Xu, L.; Han, S.-J.; Wilson, R.J.; Hall, D.A.; Osterfeld, S.J.; Yu, H.; Wang, S.X. Quantification of protein interactions and solution transport using high-density GMR sensor arrays. Nat. Nanotechnol. 2011, 6, 314-320. [CrossRef] [PubMed]

13. Chung, H.J.; Castro, C.M.; Im, H.; Lee, H.; Weissleder, R. A magneto-DNA nanoparticle system for rapid detection and phenotyping of bacteria. Nat. Nanotechnol. 2013, 8, 369-375. [CrossRef] [PubMed]

14. Xu, S.; Yashchuk, V.V.; Donaldson, M.H.; Rochester, S.M.; Budker, D.; Pines, A. Magnetic resonance imaging with an optical atomic magnetometer. Proc. Natl. Acad. Sci. USA 2006, 103, 12668-12671. [CrossRef] [PubMed]

15. Shen, W.; Schrag, B.D.; Carter, M.J.; Xie, J.; Xu, C.; Sun, S.; Xiao, G. Detection of DNA labeled with magnetic nanoparticles using MgO-based magnetic tunnel junction sensors. J. Appl. Phys. 2008, 103, 07A306. [CrossRef]

16. Ejsing, L.; Hansen, M.F.; Menon, A.K.; Ferreira, H.A.; Graham, D.L.; Freitas, P.P. Magnetic microbead detection using the planar Hall effect. J. Magn. Magn. Mater. 2005, 293, 677-684. [CrossRef]

17. Ludwig, F.; Mäuselein, S.; Heim, E.; Schilling, M. Magnetorelaxometry of magnetic nanoparticles in magnetically unshielded environment utilizing a differential fluxgate arrangement. Rev. Sci. Instrum. 2005, 76, 106102. [CrossRef]

18. Pellicer-Guridi, R.; Vogel, M.W.; Reutens, D.C.; Vegh, V. Towards ultimate low frequency air-core magnetometer sensitivity. Sci. Rep. 2017, 7, 2269. [CrossRef] [PubMed]

19. Vavassori, P.; Metlushko, V.; Ilic, B.; Gobbi, M.; Donolato, M.; Cantoni, M.; Bertacco, R. Domain wall displacement in Py square ring for single nanometric magnetic bead detection. Appl. Phys. Lett. 2008, 93, 203502. [CrossRef]

20. Liu, J.P. Nanoscale Magnetic Materials and Applications; Springer: New York, NY, USA, 2009; p. 719. 
21. Kenning, G.G.; Rodriguez, R.; Zotev, V.S.; Moslemi, A.; Wilson, S.; Hawel, L.; Byus, C.; Kovach, J.S. Detection of magnetically enhanced cancer tumors using SQUID magnetometry: A feasibility study. Rev. Sci. Instrum. 2005, 76, 014303. [CrossRef]

22. Chemla, Y.R.; Grossman, H.L.; Poon, Y.; McDermott, R.; Stevens, R.; Alper, M.D.; Clarke, J. Ultrasensitive magnetic biosensor for homogeneous immunoassay. Proc. Natl. Acad. Sci. USA 2000, 97, 14268-14272. [CrossRef] [PubMed]

23. Johnson, C.; Adolphi, N.L.; Butler, K.L.; Lovato, D.M.; Larson, R.; Schwindt, P.D.D.; Flynn, E.R. Magnetic relaxometry with an atomic magnetometer and SQUID sensors on targeted cancer cells. J. Magn. Magn. Mater. 2012, 324, 2613-2619. [CrossRef] [PubMed]

24. Kotitz, R.; Matz, H.; Trahms, L.; Koch, H.; Weitschies, W.; Rheinlander, T.; Semmler, W.; Bunte, T. SQUID based remanence measurements for immunoassays. IEEE Trans. Appl. Supercond. 1997, 7, 3678-3681. [CrossRef]

25. Yao, L.; Xu, S. Force-induced remnant magnetization spectroscopy for specific magnetic imaging of molecules. Angew. Chem. Int. Ed. 2011, 50, 4407-4409. [CrossRef] [PubMed]

26. Krause, H.-J.; Wolters, N.; Zhang, Y.; Offenhäusser, A.; Miethe, P.; Meyer, M.H.F.; Hartmann, M.; Keusgen, M. Magnetic particle detection by frequency mixing for immunoassay applications. J. Magn. Magn. Mater. 2007, 311, 436-444. [CrossRef]

27. Kolhatkar, A.G.; Jamison, A.C.; Litvinov, D.; Willson, R.C.; Lee, T.R. Tuning the magnetic properties of nanoparticles. Int. J. Mol. Sci. 2013, 14, 15977-16009. [CrossRef] [PubMed]

28. Jeong, U.; Teng, X.; Wang, Y.; Yang, H.; Xia, Y. Superparamagnetic colloids: Controlled synthesis and niche applications. Adv. Mater. 2007, 19, 33-60. [CrossRef]

29. Cullity, B.D.; Graham, C.D. Introduction to Magnetic Materials, 2nd ed.; IEEE/Wiley: Hoboken, NJ, USA, 2009; p. 544.

30. Neuman, K.C.; Nagy, A. Single-molecule force spectroscopy: Optical tweezers, magnetic tweezers and atomic force microscopy. Nat. Methods 2008, 5, 491-505. [CrossRef] [PubMed]

31. Kim, B.H.; Lee, N.; Kim, H.; An, K.; Park, Y.I.; Choi, Y.; Shin, K.; Lee, Y.; Kwon, S.G.; Na, H.B.; et al. Large-scale synthesis of uniform and extremely small-sized iron oxide nanoparticles for high-resolution $\mathrm{T}_{1}$ magnetic resonance imaging contrast agents. J. Am. Chem. Soc. 2011, 133, 12624-12631. [CrossRef] [PubMed]

32. Wei, H.; Insin, N.; Lee, J.; Han, H.-S.; Cordero, J.M.; Liu, W.; Bawendi, M.G. Compact zwitterion-coated iron oxide nanoparticles for biological applications. Nano Lett. 2012, 12, 22-25. [CrossRef] [PubMed]

33. Wang, L.; Bao, J.; Wang, L.; Zhang, F.; Li, Y. One-pot synthesis and bioapplication of amine-functionalized magnetite nanoparticles and hollow nanospheres. Chem. A Eur. J. 2006, 12, 6341-6347. [CrossRef] [PubMed]

34. Lin, P.-C.; Chou, P.-H.; Chen, S.-H.; Liao, H.-K.; Wang, K.-Y.; Chen, Y.-J.; Lin, C.-C. Ethylene glycol-protected magnetic nanoparticles for a multiplexed immunoassay in human plasma. Small 2006, 2, 485-489. [CrossRef] [PubMed]

35. Leslie-Pelecky, D.L.; Rieke, R.D. Magnetic properties of nanostructured materials. Chem. Mater. 1996, 8, 1770-1783. [CrossRef]

36. Fortin, J.-P.; Wilhelm, C.; Servais, J.; Ménager, C.; Bacri, J.-C.; Gazeau, F. Size-sorted anionic iron oxide nanomagnets as colloidal mediators for magnetic hyperthermia. J. Am. Chem. Soc. 2007, 129, 2628-2635. [CrossRef] [PubMed]

37. Mahmoudi, M.; Hosseinkhani, H.; Hosseinkhani, M.; Boutry, S.; Simchi, A.; Journeay, W.S.; Subramani, K.; Laurent, S. Magnetic resonance imaging tracking of stem cells in vivo using iron oxide nanoparticles as a tool for the advancement of clinical regenerative medicine. Chem. Rev. 2011, 111, 253-280. [CrossRef] [PubMed]

38. Jun, Y.-W.; Lee, J.-H.; Cheon, J. Chemical design of nanoparticle probes for high-performance magnetic resonance imaging. Angew. Chem. Int. Ed. 2008, 47, 5122-5135. [CrossRef] [PubMed]

39. Sun, C.; Lee, J.S.H.; Zhang, M. Magnetic nanoparticles in MR imaging and drug delivery. Adv. Drug Deliv. Rev. 2008, 60, 1252-1265. [CrossRef] [PubMed]

40. Perez, J.M.; Josephson, L.; O'Loughlin, T.; Hogemann, D.; Weissleder, R. Magnetic relaxation switches capable of sensing molecular interactions. Nat. Biotechnol. 2002, 20, 816-820. [CrossRef] [PubMed]

41. Liu, J.; Qiao, S.Z.; Hu, Q.H.; Lu, G.Q. Magnetic nanocomposites with mesoporous structures: Synthesis and applications. Small 2011, 7, 425-443. [CrossRef] [PubMed] 
42. Pinho, S.L.C.; Pereira, G.A.; Voisin, P.; Kassem, J.; Bouchaud, V.; Etienne, L.; Peters, J.A.; Carlos, L.; Mornet, S.; Geraldes, C.F.G.C.; et al. Fine tuning of the relaxometry of $\gamma-\mathrm{Fe}_{2} \mathrm{O}_{3} @ \mathrm{SiO}_{2}$ nanoparticles by tweaking the silica coating thickness. ACS Nano 2010, 4, 5339-5349. [CrossRef] [PubMed]

43. Philipse, A.P.; van Bruggen, M.P.B.; Pathmamanoharan, C. Magnetic silica dispersions: Preparation and stability of surface-modified silica particles with a magnetic core. Langmuir 1994, 10, 92-99. [CrossRef]

44. Yang, C.; Wang, G.; Lu, Z.; Sun, J.; Zhuang, J.; Yang, W. Effect of ultrasonic treatment on dispersibility of $\mathrm{Fe}_{3} \mathrm{O}_{4}$ nanoparticles and synthesis of multi-core $\mathrm{Fe}_{3} \mathrm{O}_{4} / \mathrm{SiO}_{2}$ core/shell nanoparticles. J. Mater. Chem. 2005, 15, 4252-4257. [CrossRef]

45. Kouassi, G.K.; Irudayaraj, J. Magnetic and gold-coated magnetic nanoparticles as a DNA sensor. Anal. Chem. 2006, 78, 3234-3241. [CrossRef] [PubMed]

46. Qu, H.; Caruntu, D.; Liu, H.; O'Connor, C.J. Water-dispersible iron oxide magnetic nanoparticles with versatile surface functionalities. Langmuir 2011, 27, 2271-2278. [CrossRef] [PubMed]

47. Mazur, M.; Barras, A.; Kuncser, V.; Galatanu, A.; Zaitzev, V.; Turcheniuk, K.V.; Woisel, P.; Lyskawa, J.; Laure, W.; Siriwardena, A.; et al. Iron oxide magnetic nanoparticles with versatile surface functions based on dopamine anchors. Nanoscale 2013, 5, 2692-2702. [CrossRef] [PubMed]

48. Kluchova, K.; Zboril, R.; Tucek, J.; Pecova, M.; Zajoncova, L.; Safarik, I.; Mashlan, M.; Markova, I.; Jancik, D.; Sebela, M.; et al. Superparamagnetic maghemite nanoparticles from solid-state synthesis-Their functionalization towards peroral MRI contrast agent and magnetic carrier for trypsin immobilization. Biomaterials 2009, 30, 2855-2863. [CrossRef] [PubMed]

49. Vreeland, E.C.; Watt, J.; Schober, G.B.; Hance, B.G.; Austin, M.J.; Price, A.D.; Fellows, B.D.; Monson, T.C.; Hudak, N.S.; Maldonado-Camargo, L.; et al. Enhanced nanoparticle size control by extending LaMer's mechanism. Chem. Mater. 2015, 27, 6059-6066. [CrossRef]

50. Rockenberger, J.; Scher, E.C.; Alivisatos, A.P. A new nonhydrolytic single-precursor approach to surfactant-capped nanocrystals of transition metal oxides. J. Am. Chem. Soc. 1999, 121, 11595-11596. [CrossRef]

51. Sun, S.; Zeng, H.; Robinson, D.B.; Raoux, S.; Rice, P.M.; Wang, S.X.; Li, G. Monodisperse $\mathrm{MFe}_{2} \mathrm{O}_{4}(\mathrm{M}=\mathrm{Fe}$, Co, Mn) nanoparticles. J. Am. Chem. Soc. 2004, 126, 273-279. [CrossRef] [PubMed]

52. De Palma, R.; Peeters, S.; Van Bael, M.J.; Van den Rul, H.; Bonroy, K.; Laureyn, W.; Mullens, J.; Borghs, G.; Maes, G. Silane ligand exchange to make hydrophobic superparamagnetic nanoparticles water-dispersible. Chem. Mater. 2007, 19, 1821-1831. [CrossRef]

53. Silke, B.; Helmut, B.; Nina, M.; Angelika, G.; Eckhard, D.; Wilhelm, H.; Jens, B.; Svetlana, Z.; Natalie, P.; Josef, H.; et al. Surface engineering of $\mathrm{Co}$ and FeCo nanoparticles for biomedical application. J. Phys. Condens. Matter 2006, 18, S2543.

54. Murray, C.B.; Sun, S.; Doyle, H.; Betley, T. Monodisperse 3d transition-metal (Co,Ni,Fe) nanoparticles and their assembly into nanoparticle superlattices. MRS Bull. 2001, 26, 985-991. [CrossRef]

55. Huber, D.L. Synthesis, properties, and applications of iron nanoparticles. Small 2005, 1, 482-501. [CrossRef] [PubMed]

56. Sun, S. Recent advances in chemical synthesis, self-assembly, and applications of FePt nanoparticles. Adv. Mater. 2006, 18, 393-403. [CrossRef]

57. Chaubey, G.S.; Barcena, C.; Poudyal, N.; Rong, C.; Gao, J.; Sun, S.; Liu, J.P. Synthesis and stabilization of FeCo nanoparticles. J. Am. Chem. Soc. 2007, 129, 7214-7215. [CrossRef] [PubMed]

58. Sun, S.; Anders, S.; Thomson, T.; Baglin, J.E.E.; Toney, M.F.; Hamann, H.F.; Murray, C.B.; Terris, B.D. Controlled synthesis and assembly of FePt nanoparticles. J. Phys. Chem. B 2003, 107, 5419-5425. [CrossRef]

59. Chen, M.; Kim, J.; Liu, J.P.; Fan, H.; Sun, S. Synthesis of FePt nanocubes and their oriented self-assembly. J. Am. Chem. Soc. 2006, 128, 7132-7133. [CrossRef] [PubMed]

60. Wang, C.; Hou, Y.; Kim, J.; Sun, S. A general strategy for synthesizing FePt nanowires and nanorods. Angew. Chem. Int. Ed. 2007, 46, 6333-6335. [CrossRef] [PubMed]

61. Kobayashi, Y.; Kakinuma, H.; Nagao, D.; Ando, Y.; Miyazaki, T.; Konno, M. Silica coating of Co-Pt alloy nanoparticles prepared in the presence of poly(vinylpyrrolidone). J. Nanopart. Res. 2009, 11, 1787-1794. [CrossRef]

62. Wang, X.; Zhuang, J.; Peng, Q.; Li, Y. A general strategy for nanocrystal synthesis. Nature 2005, 437, $121-124$. [CrossRef] [PubMed] 
63. Hachani, R.; Lowdell, M.; Birchall, M.; Hervault, A.; Mertz, D.; Begin-Colin, S.; Thanh, N.T.K. Polyol synthesis, functionalisation, and biocompatibility studies of superparamagnetic iron oxide nanoparticles as potential MRI contrast agents. Nanoscale 2016, 8, 3278-3287. [CrossRef] [PubMed]

64. Deng, H.; Li, X.; Peng, Q.; Wang, X.; Chen, J.; Li, Y. Monodisperse magnetic single-crystal ferrite microspheres. Angew. Chem. Int. Ed. 2005, 44, 2782-2785. [CrossRef] [PubMed]

65. Xuan, S.; Wang, Y.-X.J.; Yu, J.C.; Cham-Fai Leung, K. Tuning the grain size and particle size of superparamagnetic $\mathrm{Fe}_{3} \mathrm{O}_{4}$ microparticles. Chem. Mater. 2009, 21, 5079-5087. [CrossRef]

66. Yang, H.-H.; Zhang, S.-Q.; Chen, X.-L.; Zhuang, Z.-X.; Xu, J.-G.; Wang, X.-R. Magnetite-containing spherical silica nanoparticles for biocatalysis and bioseparations. Anal. Chem. 2004, 76, 1316-1321. [CrossRef] [PubMed]

67. Cho, S.-J.; Kauzlarich, S.M.; Olamit, J.; Liu, K.; Grandjean, F.; Rebbouh, L.; Long, G.J. Characterization and magnetic properties of core/shell structured Fe/Au nanoparticles. J. Appl. Phys. 2004, 95, 6804-6806. [CrossRef]

68. Liu, C.; Zou, B.; Rondinone, A.J.; Zhang, Z.J. Reverse micelle synthesis and characterization of superparamagnetic $\mathrm{MnFe}_{2} \mathrm{O}_{4}$ spinel ferrite nanocrystallites. J. Phys. Chem. B 2000, 104, 1141-1145. [CrossRef]

69. Lee, Y.; Lee, J.; Bae, C.J.; Park, J.G.; Noh, H.J.; Park, J.H.; Hyeon, T. Large-scale synthesis of uniform and crystalline magnetite nanoparticles using reverse micelles as nanoreactors under reflux conditions. Adv. Funct. Mater. 2005, 15, 503-509. [CrossRef]

70. Salgueiriño-Maceira, V.; Spasova, M.; Farle, M. Water-stable, magnetic silica-cobalt/cobalt oxide-silica multishell submicrometer spheres. Adv. Funct. Mater. 2005, 15, 1036-1040. [CrossRef]

71. Wang, J.; Loh, K.P.; Zhong, Y.L.; Lin, M.; Ding, J.; Foo, Y.L. Bifunctional FePt core-shell and hollow spheres: Sonochemical preparation and self-assembly. Chem. Mater. 2007, 19, 2566-2572. [CrossRef]

72. Stoeva, S.I.; Huo, F.; Lee, J.-S.; Mirkin, C.A. Three-layer composite magnetic nanoparticle probes for DNA. J. Am. Chem. Soc. 2005, 127, 15362-15363. [CrossRef] [PubMed]

73. Amara, D.; Margel, S. Synthesis and characterization of superparamagnetic core-shell micrometre-sized particles of narrow size distribution by a swelling process. J. Mater. Chem. 2012, 22, 9268-9276. [CrossRef]

74. Qiao, R.; Yang, C.; Gao, M. Superparamagnetic iron oxide nanoparticles: From preparations to in vivo MRI applications. J. Mater. Chem. 2009, 19, 6274-6293. [CrossRef]

75. Laurent, S.; Forge, D.; Port, M.; Roch, A.; Robic, C.; Vander Elst, L.; Muller, R.N. Magnetic iron oxide nanoparticles: Synthesis, stabilization, vectorization, physicochemical characterizations, and biological applications. Chem. Rev. 2008, 108, 2064-2110. [CrossRef] [PubMed]

76. Xu, H.; Cui, L.; Tong, N.; Gu, H. Development of high magnetization $\mathrm{Fe}_{3} \mathrm{O}_{4}$ / polystyrene/silica nanospheres via combined miniemulsion/emulsion polymerization. J. Am. Chem. Soc. 2006, 128, 15582-15583. [CrossRef] [PubMed]

77. Stappert, S.; Rellinghaus, B.; Acet, M.; Wassermann, E.F. Gas-phase preparation of L10 ordered FePt nanoparticles. J. Cryst. Growth 2003, 252, 440-450. [CrossRef]

78. Wei, X.-W.; Zhu, G.-X.; Liu, Y.-J.; Ni, Y.-H.; Song, Y.; Xu, Z. Large-scale controlled synthesis of FeCo nanocubes and microcages by wet chemistry. Chem. Mater. 2008, 20, 6248-6253. [CrossRef]

79. Kolhatkar, A.G.; Nekrashevich, I.; Litvinov, D.; Willson, R.C.; Lee, T.R. Cubic silica-coated and amine-functionalized FeCo nanoparticles with high saturation magnetization. Chem. Mater. 2013, 25, 1092-1097. [CrossRef] [PubMed]

80. Liu, C.; Wu, X.; Klemmer, T.; Shukla, N.; Yang, X.; Weller, D.; Roy, A.G.; Tanase, M.; Laughlin, D. Polyol process synthesis of monodispersed FePt nanoparticles. J. Phys. Chem. B 2004, 108, 6121-6123. [CrossRef] [PubMed]

81. Lu, A.-H.; Salabas, E.L.; Schüth, F. Magnetic nanoparticles: Synthesis, protection, functionalization, and application. Angew. Chem. Int. Ed. 2007, 46, 1222-1244. [CrossRef] [PubMed]

82. Liong, M.; Lu, J.; Kovochich, M.; Xia, T.; Ruehm, S.G.; Nel, A.E.; Tamanoi, F.; Zink, J.I. Multifunctional inorganic nanoparticles for imaging, targeting, and drug delivery. ACS Nano 2008, 2, 889-896. [CrossRef] [PubMed]

83. Bruce, I.J.; Taylor, J.; Todd, M.; Davies, M.J.; Borioni, E.; Sangregorio, C.; Sen, T. Synthesis, characterisation and application of silica-magnetite nanocomposites. J. Magn. Magn. Mater. 2004, 284, 145-160. [CrossRef] 
84. Li, G.; Joshi, V.; White, R.L.; Wang, S.X.; Kemp, J.T.; Webb, C.; Davis, R.W.; Sun, S. Detection of single micron-sized magnetic bead and magnetic nanoparticles using spin valve sensors for biological applications. J. Appl. Phys. 2003, 93, 7557-7559. [CrossRef]

85. Shubayev, V.I.; Pisanic, T.R., II; Jin, S. Magnetic nanoparticles for theragnostics. Adv. Drug Deliv. Rev. 2009, 61,467-477. [CrossRef] [PubMed]

86. Singh, N.; Jenkins, G.J.S.; Asadi, R.; Doak, S.H. Potential toxicity of superparamagnetic iron oxide nanoparticles (spion). Nano Rev. 2010, 1, 5358. [CrossRef] [PubMed]

87. Seo, W.S.; Lee, J.H.; Sun, X.; Suzuki, Y.; Mann, D.; Liu, Z.; Terashima, M.; Yang, P.C.; McConnell, M.V.; Nishimura, D.G.; et al. FeCo/graphitic-shell nanocrystals as advanced magnetic-resonance-imaging and near-infrared agents. Nat. Mater. 2006, 5, 971-976. [CrossRef] [PubMed]

88. Markides, H.; Rotherham, M.; El Haj, A.J. Biocompatibility and toxicity of magnetic nanoparticles in regenerative medicine. J. Nanomater. 2012, 2012, 11. [CrossRef]

89. Nel, A.E.; Mädler, L.; Velegol, D.; Xia, T.; Hoek, E.M.V.; Somasundaran, P.; Klaessig, F.; Castranova, V.; Thompson, M. Understanding biophysicochemical interactions at the nano-bio interface. Nat. Mater. 2009, 8, 543-557. [CrossRef] [PubMed]

90. Chin, S.F.; Iyer, K.S.; Raston, C.L. Facile and green approach to fabricate gold and silver coated superparamagnetic nanoparticles. Cryst. Growth Des. 2009, 9, 2685-2689. [CrossRef]

91. Li, W.; Deng, Y.; Wu, Z.; Qian, X.; Yang, J.; Wang, Y.; Gu, D.; Zhang, F.; Tu, B.; Zhao, D. Hydrothermal etching assisted crystallization: A facile route to functional yolk-shell titanate microspheres with ultrathin nanosheets-assembled double shells. J. Am. Chem. Soc. 2011, 133, 15830-15833. [CrossRef] [PubMed]

92. Tang, D.; Yuan, R.; Chai, Y. Magnetic core-shell $\mathrm{Fe}_{3} \mathrm{O}_{4} @ \mathrm{Ag}$ nanoparticles coated carbon paste interface for studies of carcinoembryonic antigen in clinical immunoassay. J. Phys. Chem. B 2006, 110, 11640-11646. [CrossRef] [PubMed]

93. Stöber, W.; Fink, A.; Bohn, E. Controlled growth of monodisperse silica spheres in the micron size range. J. Colloid Interface Sci. 1968, 26, 62-69. [CrossRef]

94. Ghosh Chaudhuri, R.; Paria, S. Core/shell nanoparticles: Classes, properties, synthesis mechanisms, characterization, and applications. Chem. Rev. 2012, 112, 2373-2433. [CrossRef] [PubMed]

95. Lu, Y.; Yin, Y.; Mayers, B.T.; Xia, Y. Modifying the surface properties of superparamagnetic iron oxide nanoparticles through a sol-gel approach. Nano Lett. 2002, 2, 183-186. [CrossRef]

96. Hui, C.; Shen, C.; Tian, J.; Bao, L.; Ding, H.; Li, C.; Tian, Y.; Shi, X.; Gao, H.-J. Core-shell $\mathrm{Fe}_{3} \mathrm{O}_{4} @ \mathrm{SiO}_{2}$ nanoparticles synthesized with well-dispersed hydrophilic $\mathrm{Fe}_{3} \mathrm{O}_{4}$ seeds. Nanoscale 2011, 3, 701-705. [CrossRef] [PubMed]

97. Cha, J.; Cui, P.; Lee, J.-K. A simple method to synthesize multifunctional silica nanocomposites, $\mathrm{NPs}_{\mathrm{S}} \mathrm{SiO}_{2}$, using polyvinylpyrrolidone (PVP) as a mediator. J. Mater. Chem. 2010, 20, 5533-5537. [CrossRef]

98. Kobayashi, Y.; Horie, M.; Konno, M.; Rodríguez-González, B.; Liz-Marzán, L.M. Preparation and properties of silica-coated cobalt nanoparticles. J. Phys. Chem. B 2003, 107, 7420-7425. [CrossRef]

99. Nagao, D.; Yokoyama, M.; Yamauchi, N.; Matsumoto, H.; Kobayashi, Y.; Konno, M. Synthesis of highly monodisperse particles composed of a magnetic core and fluorescent shell. Langmuir 2008, 24, 9804-9808. [CrossRef] [PubMed]

100. Ding, H.L.; Zhang, Y.X.; Wang, S.; Xu, J.M.; Xu, S.C.; Li, G.H. $\mathrm{Fe}_{3} \mathrm{O}_{4} @ \mathrm{SiO}_{2}$ core/shell nanoparticles: The silica coating regulations with a single core for different core sizes and shell thicknesses. Chem. Mater. 2012, 24, 4572-4580. [CrossRef]

101. Yue, Q.; Li, J.; Luo, W.; Zhang, Y.; Elzatahry, A.A.; Wang, X.; Wang, C.; Li, W.; Cheng, X.; Alghamdi, A.; et al. An interface coassembly in biliquid phase: Toward core-shell magnetic mesoporous silica microspheres with tunable pore size. J. Am. Chem. Soc. 2015, 137, 13282-13289. [CrossRef] [PubMed]

102. Jiao, Y.; Sun, Y.; Tang, X.; Ren, Q.; Yang, W. Tumor-targeting multifunctional rattle-type theranostic nanoparticles for MRI/NIRF bimodal imaging and delivery of hydrophobic drugs. Small 2015, 11, 1962-1974. [CrossRef] [PubMed]

103. Li, W.-P.; Liao, P.-Y.; Su, C.-H.; Yeh, C.-S. Formation of oligonucleotide-gated silica shell-coated $\mathrm{Fe}_{3} \mathrm{O}_{4}-\mathrm{Au}$ core-shell nanotrisoctahedra for magnetically targeted and near-infrared light-responsive theranostic platform. J. Am. Chem. Soc. 2014, 136, 10062-10075. [CrossRef] [PubMed] 
104. Wang, D.-W.; Zhu, X.-M.; Lee, S.-F.; Chan, H.-M.; Li, H.-W.; Kong, S.K.; Yu, J.C.; Cheng, C.H.K.; Wang, Y.-X.J.; Leung, K.C.-F. Folate-conjugated $\mathrm{Fe}_{3} \mathrm{O}_{4} @ \mathrm{SiO}_{2} @$ gold nanorods@mesoporous $\mathrm{SiO}_{2}$ hybrid nanomaterial: A theranostic agent for magnetic resonance imaging and photothermal therapy. J. Mater. Chem. B 2013, 1, 2934-2942. [CrossRef]

105. Wang, L.; Luo, J.; Maye, M.M.; Fan, Q.; Rendeng, Q.; Engelhard, M.H.; Wang, C.; Lin, Y.; Zhong, C.-J. Iron oxide-gold core-shell nanoparticles and thin film assembly. J. Mater. Chem. 2005, 15, 1821-1832. [CrossRef]

106. Ji, X.; Shao, R.; Elliott, A.M.; Stafford, R.J.; Esparza-Coss, E.; Bankson, J.A.; Liang, G.; Luo, Z.-P.; Park, K.; Markert, J.T.; et al. Bifunctional gold nanoshells with a superparamagnetic iron oxide-silica core suitable for both MR imaging and photothermal therapy. J. Phys. Chem. C 2007, 111, 6245-6251. [CrossRef] [PubMed]

107. Melancon, M.P.; Lu, W.; Li, C. Gold-based magneto/optical nanostructures: Challenges for in vivo applications in cancer diagnostics and therapy. MRS Bull. 2009, 34, 415-421. [CrossRef]

108. Xu, Z.; Li, C.; Kang, X.; Yang, D.; Yang, P.; Hou, Z.; Lin, J. Synthesis of a multifunctional nanocomposite with magnetic, mesoporous, and near-IR absorption properties. J. Phys. Chem. C 2010, 114, 16343-16350. [CrossRef]

109. Deng, Y.; Cai, Y.; Sun, Z.; Liu, J.; Liu, C.; Wei, J.; Li, W.; Liu, C.; Wang, Y.; Zhao, D. Multifunctional mesoporous composite microspheres with well-designed nanostructure: A highly integrated catalyst system. J. Am. Chem. Soc. 2010, 132, 8466-8473. [CrossRef] [PubMed]

110. Krüger, S.; Stener, M.; Rösch, N. Relativistic density functional study of gold coated magnetic nickel clusters. J. Chem. Phys. 2001, 114, 5207-5215. [CrossRef]

111. Huang, X.; Zhuang, J.; Chen, D.; Liu, H.; Tang, F.; Yan, X.; Meng, X.; Zhang, L.; Ren, J. General strategy for designing functionalized magnetic microspheres for different bioapplications. Langmuir 2009, 25, 11657-11663. [CrossRef] [PubMed]

112. Shultz, M.D.; Reveles, J.U.; Khanna, S.N.; Carpenter, E.E. Reactive nature of dopamine as a surface functionalization agent in iron oxide nanoparticles. J. Am. Chem. Soc. 2007, 129, 2482-2487. [CrossRef] [PubMed]

113. Huang, X.; Schmucker, A.; Dyke, J.; Hall, S.M.; Retrum, J.; Stein, B.; Remmes, N.; Baxter, D.V.; Dragnea, B.; Bronstein, L.M. Magnetic nanoparticles with functional silanes: Evolution of well-defined shells from anhydride containing silane. J. Mater. Chem. 2009, 19, 4231-4239. [CrossRef] [PubMed]

114. Li, D.; Teoh, W.Y.; Gooding, J.J.; Selomulya, C.; Amal, R. Functionalization strategies for protease immobilization on magnetic nanoparticles. Adv. Funct. Mater. 2010, 20, 1767-1777. [CrossRef]

115. Yoon, T.-J.; Yu, K.N.; Kim, E.; Kim, J.S.; Kim, B.G.; Yun, S.-H.; Sohn, B.-H.; Cho, M.-H.; Lee, J.-K.; Park, S.B. Specific targeting, cell sorting, and bioimaging with smart magnetic silica core-shell nanomaterials. Small 2006, 2, 209-215. [CrossRef] [PubMed]

116. Bardhan, R.; Chen, W.; Perez-Torres, C.; Bartels, M.; Huschka, R.M.; Zhao, L.L.; Morosan, E.; Pautler, R.G.; Joshi, A.; Halas, N.J. Nanoshells with targeted simultaneous enhancement of magnetic and optical imaging and photothermal therapeutic response. Adv. Funct. Mater. 2009, 19, 3901-3909. [CrossRef]

117. Sharma, R.; Xu, Y.; Kim, S.W.; Schueller, M.J.; Alexoff, D.; Smith, S.D.; Wang, W.; Schlyer, D. Carbon-11 radiolabeling of iron-oxide nanoparticles for dual-modality PET/MR imaging. Nanoscale 2013, 5, 7476-7483. [CrossRef] [PubMed]

118. Fang, C.; Bhattarai, N.; Sun, C.; Zhang, M. Functionalized nanoparticles with long-term stability in biological media. Small 2009, 5, 1637-1641. [CrossRef] [PubMed]

119. Xu, C.; Xu, K.; Gu, H.; Zheng, R.; Liu, H.; Zhang, X.; Guo, Z.; Xu, B. Dopamine as a robust anchor to immobilize functional molecules on the iron oxide shell of magnetic nanoparticles. J. Am. Chem. Soc. 2004, 126, 9938-9939. [CrossRef] [PubMed]

120. White, M.A.; Johnson, J.A.; Koberstein, J.T.; Turro, N.J. Toward the syntheses of universal ligands for metal oxide surfaces: Controlling surface functionality through click chemistry. J. Am. Chem. Soc. 2006, 128, 11356-11357. [CrossRef] [PubMed]

121. Boyer, C.; Priyanto, P.; Davis, T.P.; Pissuwan, D.; Bulmus, V.; Kavallaris, M.; Teoh, W.Y.; Amal, R.; Carroll, M.; Woodward, R.; et al. Anti-fouling magnetic nanoparticles for siRNA delivery. J. Mater. Chem. 2010, 20, 255-265. [CrossRef]

122. Boyer, C.; Bulmus, V.; Priyanto, P.; Teoh, W.Y.; Amal, R.; Davis, T.P. The stabilization and bio-functionalization of iron oxide nanoparticles using heterotelechelic polymers. J. Mater. Chem. 2009, 19, 111-123. [CrossRef] 
123. N'Guyen, T.T.T.; Duong, H.T.T.; Basuki, J.; Montembault, V.; Pascual, S.; Guibert, C.; Fresnais, J.; Boyer, C.; Whittaker, M.R.; Davis, T.P.; et al. Functional iron oxide magnetic nanoparticles with hyperthermia-induced drug release ability by using a combination of orthogonal click reactions. Angew. Chem. Int. Ed. 2013, 52, 14152-14156. [CrossRef] [PubMed]

124. Manasmita, D.; Debasish, M.; Maiti, T.K.; Basak, A.; Pramanik, P. Bio-functionalization of magnetite nanoparticles using an aminophosphonic acid coupling agent: New, ultradispersed, iron-oxide folate nanoconjugates for cancer-specific targeting. Nanotechnology 2008, 19, 415101.

125. Hatakeyama, M.; Kishi, H.; Kita, Y.; Imai, K.; Nishio, K.; Karasawa, S.; Masaike, Y.; Sakamoto, S.; Sandhu, A.; Tanimoto, A.; et al. A two-step ligand exchange reaction generates highly water-dispersed magnetic nanoparticles for biomedical applications. J. Mater. Chem. 2011, 21, 5959-5966. [CrossRef]

126. Liu, Y.; Chen, T.; Wu, C.; Qiu, L.; Hu, R.; Li, J.; Cansiz, S.; Zhang, L.; Cui, C.; Zhu, G.; et al. Facile surface functionalization of hydrophobic magnetic nanoparticles. J. Am. Chem. Soc. 2014, 136, 12552-12555. [CrossRef] [PubMed]

127. Thanh, N.T.K.; Green, L.A.W. Functionalisation of nanoparticles for biomedical applications. Nano Today 2010, 5, 213-230. [CrossRef]

128. Josephson, L.; Tung, C.-H.; Moore, A.; Weissleder, R. High-efficiency intracellular magnetic labeling with novel superparamagnetic-Tat peptide conjugates. Bioconjug. Chem. 1999, 10, 186-191. [CrossRef] [PubMed]

129. Xu, Y.; Qin, Y.; Palchoudhury, S.; Bao, Y. Water-soluble iron oxide nanoparticles with high stability and selective surface functionality. Langmuir 2011, 27, 8990-8997. [CrossRef] [PubMed]

130. Wang, X.; Wei, F.; Liu, A.; Wang, L.; Wang, J.-C.; Ren, L.; Liu, W.; Tu, Q.; Li, L.; Wang, J. Cancer stem cell labeling using poly(l-lysine)-modified iron oxide nanoparticles. Biomaterials 2012, 33, 3719-3732. [CrossRef] [PubMed]

131. Kim, H.M.; Lee, H.; Hong, K.S.; Cho, M.Y.; Sung, M.-H.; Poo, H.; Lim, Y.T. Synthesis and high performance of magnetofluorescent polyelectrolyte nanocomposites as MR/near-infrared multimodal cellular imaging nanoprobes. ACS Nano 2011, 5, 8230-8240. [CrossRef] [PubMed]

132. Liu, S.; Han, Y.; Qiao, R.; Zeng, J.; Jia, Q.; Wang, Y.; Gao, M. Investigations on the interactions between plasma proteins and magnetic iron oxide nanoparticles with different surface modifications. J. Phys. Chem. C 2010, 114, 21270-21276. [CrossRef]

133. Lutz, J.-F.; Stiller, S.; Hoth, A.; Kaufner, L.; Pison, U.; Cartier, R. One-pot synthesis of PEGylated ultrasmall iron-oxide nanoparticles and their in vivo evaluation as magnetic resonance imaging contrast agents. Biomacromolecules 2006, 7, 3132-3138. [CrossRef] [PubMed]

134. Le Droumaguet, B.; Nicolas, J.; Brambilla, D.; Mura, S.; Maksimenko, A.; De Kimpe, L.; Salvati, E.; Zona, C.; Airoldi, C.; Canovi, M.; et al. Versatile and efficient targeting using a single nanoparticulate platform: Application to cancer and Alzheimer's disease. ACS Nano 2012, 6, 5866-5879. [CrossRef] [PubMed]

135. Sun, C.; Du, K.; Fang, C.; Bhattarai, N.; Veiseh, O.; Kievit, F.; Stephen, Z.; Lee, D.; Ellenbogen, R.G.; Ratner, B.; et al. PEG-mediated synthesis of highly dispersive multifunctional superparamagnetic nanoparticles: Their physicochemical properties and function in vivo. ACS Nano 2010, 4, 2402-2410. [CrossRef] [PubMed]

136. Amstad, E.; Zurcher, S.; Mashaghi, A.; Wong, J.Y.; Textor, M.; Reimhult, E. Surface functionalization of single superparamagnetic iron oxide nanoparticles for targeted magnetic resonance imaging. Small 2009, 5, 1334-1342. [CrossRef] [PubMed]

137. Yu, S.; Chow, G.M. Carboxyl group $\left(-\mathrm{CO}_{2} \mathrm{H}\right)$ functionalized ferrimagnetic iron oxide nanoparticles for potential bio-applications. J. Mater. Chem. 2004, 14, 2781-2786. [CrossRef]

138. Chen, H.; Deng, C.; Zhang, X. Synthesis of $\mathrm{Fe}_{3} \mathrm{O}_{4} @ \mathrm{SiO}_{2} @ \mathrm{PMMA}$ core-shell-shell magnetic microspheres for highly efficient enrichment of peptides and proteins for MALDI-ToF MS analysis. Angew. Chem. Int. Ed. 2010, 49, 607-611. [CrossRef] [PubMed]

139. Chen, H.; Wu, X.; Duan, H.; Wang, Y.A.; Wang, L.; Zhang, M.; Mao, H. Biocompatible polysiloxane-containing diblock copolymer PEO-b-P $\gamma$ MPS for coating magnetic nanoparticles. ACS Appl. Mater. Interfaces 2009, 1, 2134-2140. [CrossRef] [PubMed]

140. Lin, L.-S.; Cong, Z.-X.; Cao, J.-B.; Ke, K.-M.; Peng, Q.-L.; Gao, J.; Yang, H.-H.; Liu, G.; Chen, X. Multifunctional $\mathrm{Fe}_{3} \mathrm{O}_{4} @$ polydopamine core-shell nanocomposites for intracellular mRNA detection and imaging-guided photothermal therapy. ACS Nano 2014, 8, 3876-3883. [CrossRef] [PubMed]

141. Li, G.L.; Mohwald, H.; Shchukin, D.G. Precipitation polymerization for fabrication of complex core-shell hybrid particles and hollow structures. Chem. Soc. Rev. 2013, 42, 3628-3646. [CrossRef] [PubMed] 
142. Ma, W.-F.; Wu, K.-Y.; Tang, J.; Li, D.; Wei, C.; Guo, J.; Wang, S.-L.; Wang, C.-C. Magnetic drug carrier with a smart pH-responsive polymer network shell for controlled delivery of doxorubicin. J. Mater. Chem. 2012, 22, 15206-15214. [CrossRef]

143. Ma, W.; Xu, S.; Li, J.; Guo, J.; Lin, Y.; Wang, C. Hydrophilic dual-responsive magnetite/PMAA core/shell microspheres with high magnetic susceptibility and $\mathrm{pH}$ sensitivity via distillation-precipitation polymerization. J. Polym. Sci. Part A Polym. Chem. 2011, 49, 2725-2733. [CrossRef]

144. Zhang, Y.; Ma, W.; Li, D.; Yu, M.; Guo, J.; Wang, C. Benzoboroxole-functionalized magnetic core/shell microspheres for highly specific enrichment of glycoproteins under physiological conditions. Small 2014, 10, 1379-1386. [CrossRef] [PubMed]

145. Zhang, Y.; Yang, Y.; Ma, W.; Guo, J.; Lin, Y.; Wang, C. Uniform magnetic core/shell microspheres functionalized with $\mathrm{Ni}^{2+}$-iminodiacetic acid for one step purification and immobilization of his-tagged enzymes. ACS Appl. Mater. Interfaces 2013, 5, 2626-2633. [CrossRef] [PubMed]

146. Sapsford, K.E.; Algar, W.R.; Berti, L.; Gemmill, K.B.; Casey, B.J.; Oh, E.; Stewart, M.H.; Medintz, I.L. Functionalizing nanoparticles with biological molecules: Developing chemistries that facilitate nanotechnology. Chem. Rev. 2013, 113, 1904-2074. [CrossRef] [PubMed]

147. Lu, H.; Yi, G.; Zhao, S.; Chen, D.; Guo, L.-H.; Cheng, J. Synthesis and characterization of multi-functional nanoparticles possessing magnetic, up-conversion fluorescence and bio-affinity properties. J. Mater. Chem. 2004, 14, 1336-1341. [CrossRef]

148. Shinkai, M. Functional magnetic particles for medical application. J. Biosci. Bioeng. 2002, 94, 606-613. [CrossRef]

149. Arsianti, M.; Lim, M.; Lou, S.N.; Goon, I.Y.; Marquis, C.P.; Amal, R. Bi-functional gold-coated magnetite composites with improved biocompatibility. J. Colloid Interface Sci. 2011, 354, 536-545. [CrossRef] [PubMed]

150. Weissleder, R.; Kelly, K.; Sun, E.Y.; Shtatland, T.; Josephson, L. Cell-specific targeting of nanoparticles by multivalent attachment of small molecules. Nat. Biotechnol. 2005, 23, 1418-1423. [CrossRef] [PubMed]

151. Graham, D.L.; Ferreira, H.A.; Feliciano, N.; Freitas, P.P.; Clarke, L.A.; Amaral, M.D. Magnetic field-assisted DNA hybridisation and simultaneous detection using micron-sized spin-valve sensors and magnetic nanoparticles. Sens. Actuators B Chem. 2005, 107, 936-944. [CrossRef]

152. Liang, Y.-C.; Chang, L.; Qiu, W.; Kolhatkar, A.G.; Vu, B.; Kourentzi, K.; Lee, T.R.; Zu, Y.; Willson, R.; Litvinov, D. Ultrasensitive magnetic nanoparticle detector for biosensor applications. Sensors 2017, 17, 1296. [CrossRef] [PubMed]

153. Qiu, W.; Chang, L.; Liang, Y.-C.; Litvinov, J.; Guo, J.; Chen, Y.-T.; Vu, B.; Kourenzi, K.; Xu, S.; Lee, T.R.; et al. Spin-valve based magnetoresistive nanoparticle detector for applications in biosensing. Sens. Actuators A Phys. 2017, 265, 174-180. [CrossRef]

154. Freitas, P.P.; Cardoso, F.A.; Martins, V.C.; Martins, S.A.M.; Loureiro, J.; Amaral, J.; Chaves, R.C.; Cardoso, S.; Fonseca, L.P.; Sebastiao, A.M.; et al. Spintronic platforms for biomedical applications. Lab Chip 2012, 12, 546-557. [CrossRef] [PubMed]

155. Hall, D.A.; Gaster, R.S.; Makinwa, K.A.A.; Wang, S.X.; Murmann, B. A 256 pixel magnetoresistive biosensor microarray in $0.18 \mu \mathrm{m}$ CMOS. IEEE J. Solid-State Circuits 2013, 48, 1290-1301. [CrossRef] [PubMed]

156. Koh, I.; Josephson, L. Magnetic nanoparticle sensors. Sensors 2009, 9, 8130-8145. [CrossRef] [PubMed]

157. Yao, L.; Xu, S.J. Detection of magnetic nanomaterials in molecular imaging and diagnosis applications. Nanotechnol. Rev. 2014, 3, 247-268. [CrossRef]

158. Osterfeld, S.J.; Yu, H.; Gaster, R.S.; Caramuta, S.; Xu, L.; Han, S.-J.; Hall, D.A.; Wilson, R.J.; Sun, S.; White, R.L.; et al. Multiplex protein assays based on real-time magnetic nanotag sensing. Proc. Natl. Acad. Sci. USA 2008, 105, 20637-20640. [CrossRef] [PubMed]

159. De Palma, R.; Reekmans, G.; Liu, C.; Wirix-Speetjens, R.; Laureyn, W.; Nilsson, O.; Lagae, L. Magnetic bead sensing platform for the detection of proteins. Anal. Chem. 2007, 79, 8669-8677. [CrossRef] [PubMed]

160. Li, Y.; Srinivasan, B.; Jing, Y.; Yao, X.; Hugger, M.A.; Wang, J.-P.; Xing, C. Nanomagnetic competition assay for low-abundance protein biomarker quantification in unprocessed human sera. J. Am. Chem. Soc. 2010, 132, 4388-4392. [CrossRef] [PubMed]

161. Carregal-Romero, S.; Caballero-Díaz, E.; Beqa, L.; Abdelmonem, A.M.; Ochs, M.; Hühn, D.; Suau, B.S.; Valcarcel, M.; Parak, W.J. Multiplexed sensing and imaging with colloidal nano- and microparticles. Annu. Rev. Anal. Chem. 2013, 6, 53-81. [CrossRef] [PubMed] 
162. Baselt, D.R.; Lee, G.U.; Natesan, M.; Metzger, S.W.; Sheehan, P.E.; Colton, R.J. A biosensor based on magnetoresistance technology. Biosens. Bioelectron. 1998, 13, 731-739. [CrossRef]

163. Miller, M.M.; Sheehan, P.E.; Edelstein, R.L.; Tamanaha, C.R.; Zhong, L.; Bounnak, S.; Whitman, L.J.; Colton, R.J. A DNA array sensor utilizing magnetic microbeads and magnetoelectronic detection. J. Magn. Magn. Mater. 2001, 225, 138-144. [CrossRef]

164. Schotter, J.; Kamp, P.B.; Becker, A.; Pühler, A.; Reiss, G.; Brückl, H. Comparison of a prototype magnetoresistive biosensor to standard fluorescent DNA detection. Biosens. Bioelectron. 2004, 19, 1149-1156. [CrossRef] [PubMed]

165. Fu, A.; Hu, W.; Xu, L.; Wilson, R.J.; Yu, H.; Osterfeld, S.J.; Gambhir, S.S.; Wang, S.X. Protein-functionalized synthetic antiferromagnetic nanoparticles for biomolecule detection and magnetic manipulation. Angew. Chem. Int. Ed. 2009, 48, 1620-1624. [CrossRef] [PubMed]

166. Hall, D.A.; Gaster, R.S.; Lin, T.; Osterfeld, S.J.; Han, S.; Murmann, B.; Wang, S.X. GMR biosensor arrays: A system perspective. Biosens. Bioelectron. 2010, 25, 2051-2057. [CrossRef] [PubMed]

167. Rizzi, G.; Østerberg, F.W.; Henriksen, A.D.; Dufva, M.; Hansen, M.F. On-chip magnetic bead-based DNA melting curve analysis using a magnetoresistive sensor. J. Magn. Magn. Mater. 2015, 380, 215-220. [CrossRef]

168. Dias, T.M.; Cardoso, F.A.; Martins, S.A.M.; Martins, V.C.; Cardoso, S.; Gaspar, J.F.; Monteiro, G.; Freitas, P.P. Implementing a strategy for on-chip detection of cell-free DNA fragments using GMR sensors: A translational application in cancer diagnostics using ALU elements. Anal. Methods 2016, 8, 119-128. [CrossRef]

169. Wang, W.; Wang, Y.; Tu, L.; Klein, T.; Feng, Y.L.; Wang, J.P. Surface modification for protein and DNA immobilization onto GMR biosensor. IEEE Trans. Magn. 2013, 49, 296-299. [CrossRef]

170. Srinivasan, B.; Li, Y.; Jing, Y.; Xing, C.; Slaton, J.; Wang, J.-P. A three-layer competition-based giant magnetoresistive assay for direct quantification of endoglin from human urine. Anal. Chem. 2011, 83, 2996-3002. [CrossRef] [PubMed]

171. Chaves, R.C.; Bensimon, D.; Freitas, P.P. Single molecule actuation and detection on a lab-on-a-chip magnetoresistive platform. J. Appl. Phys. 2011, 109, 064702. [CrossRef]

172. Grancharov, S.G.; Zeng, H.; Sun, S.; Wang, S.X.; O’Brien, S.; Murray, C.B.; Kirtley, J.R.; Held, G.A. Bio-functionalization of monodisperse magnetic nanoparticles and their use as biomolecular labels in a magnetic tunnel junction based sensor. J. Phys. Chem. B 2005, 109, 13030-13035. [CrossRef] [PubMed]

173. Lei, Z.Q.; Li, L.; Li, G.J.; Leung, C.W.; Shi, J.; Wong, C.M.; Lo, K.C.; Chan, W.K.; Mak, C.S.K.; Chan, S.B.; et al. Liver cancer immunoassay with magnetic nanoparticles and $\mathrm{MgO}$-based magnetic tunnel junction sensors. J. Appl. Phys. 2012, 111, 07E505. [CrossRef]

174. Albon, C.; Weddemann, A.; Auge, A.; Rott, K.; Hütten, A. Tunneling magnetoresistance sensors for high resolutive particle detection. Appl. Phys. Lett. 2009, 95, 023101. [CrossRef]

175. Cousins, A.; Balalis, G.L.; Thompson, S.K.; Forero Morales, D.; Mohtar, A.; Wedding, A.B.; Thierry, B. Novel handheld magnetometer probe based on magnetic tunnelling junction sensors for intraoperative sentinel lymph node identification. Sci. Rep. 2015, 5, 10842. [CrossRef] [PubMed]

176. Sharma, P.P.; Albisetti, E.; Massetti, M.; Scolari, M.; La Torre, C.; Monticelli, M.; Leone, M.; Damin, F.; Gervasoni, G.; Ferrari, G.; et al. Integrated platform for detecting pathogenic DNA via magnetic tunneling junction-based biosensors. Sens. Actuators B Chem. 2017, 242, 280-287. [CrossRef]

177. Ejsing, L.; Hansen, M.F.; Menon, A.K.; Ferreira, H.A.; Graham, D.L.; Freitas, P.P. Planar Hall effect sensor for magnetic micro- and nanobead detection. Appl. Phys. Lett. 2004, 84, 4729-4731. [CrossRef]

178. Damsgaard, C.D.; Dalslet, B.T.; Freitas, S.C.; Freitas, P.P.; Hansen, M.F. Temperature effects in exchange-biased planar Hall sensors for bioapplications. Sens. Actuators A Phys. 2009, 156, 103-108. [CrossRef]

179. O/sterberg, F.W.; Dalslet, B.T.; Snakenborg, D.; Johansson, C.; Hansen, M.F. Chip-based measurements of Brownian relaxation of magnetic beads using a planar Hall effect magnetic field sensor. AIP Conf. Proc. 2010, 1311, 176-183.

180. Dalslet, B.T.; Damsgaard, C.D.; Donolato, M.; Stromme, M.; Stromberg, M.; Svedlindh, P.; Hansen, M.F. Bead magnetorelaxometry with an on-chip magnetoresistive sensor. Lab Chip 2011, 11, 296-302. [CrossRef] [PubMed]

181. Hung, T.Q.; Oh, S.; Jeong, J.-R.; Kim, C. Spin-valve planar Hall sensor for single bead detection. Sens. Actuators A Phys. 2010, 157, 42-46. [CrossRef]

182. Volmer, M.; Avram, M. Microbeads detection using spin-valve planar Hall effect sensors. J. Nanosci. Nanotechnol. 2012, 12, 7456-7459. [CrossRef] [PubMed] 
183. Østerberg, F.W.; Rizzi, G.; Zardán Gómez de la Torre, T.; Strömberg, M.; Strømme, M.; Svedlindh, P.; Hansen, M.F. Measurements of Brownian relaxation of magnetic nanobeads using planar Hall effect bridge sensors. Biosens. Bioelectron. 2013, 40, 147-152. [CrossRef] [PubMed]

184. Østerberg, F.W.; Rizzi, G.; Henriksen, A.D.; Hansen, M.F. Planar Hall effect bridge geometries optimized for magnetic bead detection. J. Appl. Phys. 2014, 115, 184505. [CrossRef]

185. Enpuku, K.; Soejima, K.; Nishimoto, T.; Matsuda, T.; Tokumitsu, H.; Tanaka, T.; Yoshinaga, K.; Kuma, H.; Hamasaki, N. Biological immunoassays without bound/free separation utilizing magnetic marker and HTS SQUID. IEEE Trans. Appl. Supercond. 2007, 17, 816-819. [CrossRef]

186. Grossman, H.L.; Myers, W.R.; Vreeland, V.J.; Bruehl, R.; Alper, M.D.; Bertozzi, C.R.; Clarke, J. Detection of bacteria in suspension by using a superconducting quantum interference device. Proc. Natl. Acad. Sci. USA 2004, 101, 129-134. [CrossRef] [PubMed]

187. Enpuku, K.; Minotani, T.; Hotta, M.; Nakahodo, A. Application of high $\mathrm{T}_{\mathrm{c}}$ SQUID magnetometer to biological immunoassays. IEEE Trans. Appl. Supercond. 2001, 11, 661-664. [CrossRef]

188. Adolphi, N.L.; Butler, K.S.; Lovato, D.M.; Tessier, T.E.; Trujillo, J.E.; Hathaway, H.J.; Fegan, D.L.; Monson, T.C.; Stevens, T.E.; Huber, D.L.; et al. Imaging of Her2-targeted magnetic nanoparticles for breast cancer detection: Comparison of SQUID-detected magnetic relaxometry and MRI. Contrast Media Mol. Imaging 2012, 7, 308-319. [CrossRef] [PubMed]

189. Kawagishi, K.; Itozaki, H.; Kondo, T.; Komori, K.; Kotitz, R. Detection of fine magnetic particles coated on a thread using an HTS-SQUID. Physics C 2004, 412, 1491-1495. [CrossRef]

190. Yang, C.-C.; Yang, S.-Y.; Chieh, J.-J.; Horng, H.-E.; Hong, C.-Y.; Yang, H.-C.; Chen, K.H.; Shih, B.Y.; Chen, T.-F.; Chiu, M.-J. Biofunctionalized magnetic nanoparticles for specifically detecting biomarkers of Alzheimer's disease in vitro. ACS Chem. Neurosci. 2011, 2, 500-505. [CrossRef] [PubMed]

191. Tanaka, S.; Ota, H.; Kondo, Y.; Tamaki, Y.; Kobayashi, S.; Noguchi, S. Detection of magnetic nanoparticles in lymph nodes of rat by high $\mathrm{T}_{\mathrm{C}}$ SQUID. IEEE Trans. Appl. Supercond. 2003, 13, 377-380. [CrossRef]

192. Shinji, K.; Takao, Y.; Ken, H.; Akira, M.; Saburo, T. Development of a new detection method for DNA molecules. Supercond. Sci. Technol. 2001, 14, 1131-1134.

193. Bhuiya, A.K.; Asai, M.; Watanabe, H.; Hirata, T.; Higuchi, Y.; Yoshida, T.; Enpuku, K. Characterization of magnetic markers and sensors for liquid-phase immunoassays using Brownian relaxation. IEEE Trans. Magn. 2012, 48, 2838-2841. [CrossRef]

194. De Silva, L.; Yao, L.; Xu, S. Mechanically resolving noncovalent bonds using acoustic radiation force. Chem. Commun. 2014, 50, 10786-10789. [CrossRef] [PubMed]

195. De Silva, L.; Yao, L.; Wang, Y.; Xu, S. Well-defined and sequence-specific noncovalent binding forces of DNA. J. Phys. Chem. B 2013, 117, 7554-7558. [CrossRef] [PubMed]

196. Yao, L.; Xu, S. Force-induced selective dissociation of noncovalent antibody-Antigen bonds. J. Phys. Chem. B 2012, 116, 9944-9948. [CrossRef] [PubMed]

197. Chen, Y.-T.; Jamison, A.C.; Lee, T.R.; Xu, S. Quantitatively resolving ligand-receptor bonds on cell surfaces using force-induced remnant magnetization spectroscopy. ACS Cent. Sci. 2016, 2, 75-79. [CrossRef] [PubMed]

198. Yao, L.; Li, Y.; Tsai, T.-W.; Xu, S.; Wang, Y. Noninvasive measurement of the mechanical force generated by motor protein Ef-G during ribosome translocation. Angew. Chem. Int. Ed. 2013, 52, 14041-14044. [CrossRef] [PubMed]

199. Yao, L.; Wang, Y.; Xu, S. Label-free microRNA detection based on exchange-induced remnant magnetization. Chem. Commun. 2013, 49, 5183-5185. [CrossRef] [PubMed]

200. Lei, J.; Lei, C.; Wang, T.; Yang, Z.; Zhou, Y. Detection of targeted carcinoembryonic antigens using a micro-fluxgate-based biosensor. Appl. Phys. Lett. 2013, 103, 203705. [CrossRef]

201. Lei, J.; Lei, C.; Wang, T.; Yang, Z.; Zhou, Y. Investigation of targeted biomolecules in a micro-fluxgate-based bio-sensing system. Biomed. Microdevices 2014, 16, 237-243. [CrossRef] [PubMed]

202. Heim, E.; Ludwig, F.; Schilling, M. Binding assays with streptavidin-functionalized superparamagnetic nanoparticles and biotinylated analytes using fluxgate magnetorelaxometry. J. Magn. Magn. Mater. 2009, 321, 1628-1631. [CrossRef]

203. Tu, L.; Jing, Y.; Li, Y.; Wang, J.-P. Real-time measurement of Brownian relaxation of magnetic nanoparticles by a mixing-frequency method. Appl. Phys. Lett. 2011, 98, 213702. [CrossRef] 
204. Nikitin, P.I.; Vetoshko, P.M.; Ksenevich, T.I. New type of biosensor based on magnetic nanoparticle detection. J. Magn. Magn. Mater. 2007, 311, 445-449. [CrossRef]

205. Hong, H.B.; Krause, H.J.; Nam, I.H.; Choi, C.J.; Shin, S.W. Magnetic immunoassay based on frequency mixing magnetic detection and magnetic particles of different magnetic properties. Anal. Methods 2014, 6, 8055-8058. [CrossRef]

206. Nahrendorf, M.; Zhang, H.; Hembrador, S.; Panizzi, P.; Sosnovik, D.E.; Aikawa, E.; Libby, P.; Swirski, F.K.; Weissleder, R. Nanoparticle PET-CT imaging of macrophages in inflammatory atherosclerosis. Circulation 2008, 117, 379-387. [CrossRef] [PubMed]

207. Cheon, J.; Lee, J.-H. Synergistically integrated nanoparticles as multimodal probes for nanobiotechnology. Acc. Chem. Res. 2008, 41, 1630-1640. [CrossRef] [PubMed]

208. Castro, C.M.; Ghazani, A.A.; Chung, J.; Shao, H.; Issadore, D.; Yoon, T.-J.; Weissleder, R.; Lee, H. Miniaturized nuclear magnetic resonance platform for detection and profiling of circulating tumor cells. Lab Chip 2014, 14, 14-23. [CrossRef] [PubMed]

209. Danieli, E.; Perlo, J.; Blümich, B.; Casanova, F. Small magnets for portable NMR spectrometers. Angew. Chem. Int. Ed. 2010, 49, 4133-4135. [CrossRef] [PubMed]

210. Zalesskiy, S.S.; Danieli, E.; Blümich, B.; Ananikov, V.P. Miniaturization of NMR systems: Desktop spectrometers, microcoil spectroscopy, and "NMR on a chip" for chemistry, biochemistry, and industry. Chem. Rev. 2014, 114, 5641-5694. [CrossRef] [PubMed]

211. Xie, J.; Jon, S. Magnetic nanoparticle-based theranostics. Theranostics 2012, 2, 122-124. [CrossRef] [PubMed]

212. Ghazani, A.A.; Pectasides, M.; Sharma, A.; Castro, C.M.; Mino-Kenudson, M.; Lee, H.; Shepard, J.-A.O.; Weissleder, R. Molecular characterization of scant lung tumor cells using iron-oxide nanoparticles and micro-nuclear magnetic resonance. Nanomed. Nanotechnol. Biol. Med. 2014, 10, 661-668. [CrossRef] [PubMed]

213. Chung, H.J.; Reiner, T.; Budin, G.; Min, C.; Liong, M.; Issadore, D.; Lee, H.; Weissleder, R. Ubiquitous detection of gram-positive bacteria with bioorthogonal magnetofluorescent nanoparticles. ACS Nano 2011, 5, 8834-8841. [CrossRef] [PubMed]

214. Shao, H.; Chung, J.; Balaj, L.; Charest, A.; Bigner, D.D.; Carter, B.S.; Hochberg, F.H.; Breakefield, X.O.; Weissleder, R.; Lee, H. Protein typing of circulating microvesicles allows real-time monitoring of glioblastoma therapy. Nat. Med. 2012, 18, 1835-1840. [CrossRef] [PubMed]

215. Drung, D.; Assmann, C.; Beyer, J.; Kirste, A.; Peters, M.; Ruede, F.; Schurig, T. Highly sensitive and easy-to-use SQUID sensors. IEEE Trans. Appl. Supercond. 2007, 17, 699-704. [CrossRef]

216. Ryhänen, T.; Seppä, H.; Ilmoniemi, R.; Knuutila, J. SQUID magnetometers for low-frequency applications. J. Low Temp. Phys. 1989, 76, 287-386. [CrossRef]

217. Song, G.; Xiangyang, S.; James, R.B., Jr.; Mark, M.B.H.; Bradford, G.O. Development of a remanence measurement-based SQUID system with in-depth resolution for nanoparticle imaging. Phys. Med. Biol. 2009, 54, N177-N188.

218. Cohen, D. Ferromagnetic contamination in the lungs and other organs of the human body. Science 1973, 180, 745-748. [CrossRef] [PubMed]

219. Lee, S.; Myers, W.R.; Grossman, H.L.; Cho, H.-M.; Chemla, Y.R.; Clarke, J. Magnetic gradiometer based on a high-transition temperature superconducting quantum interference device for improved sensitivity of a biosensor. Appl. Phys. Lett. 2002, 81, 3094-3096. [CrossRef]

220. Matz, H.; Drung, D.; Hartwig, S.; Groß, H.; Kötitz, R.; Müller, W.; Vass, A.; Weitschies, W.; Trahms, L. A SQUID measurement system for immunoassays. Appl. Supercond. 1999, 6, 577-583. [CrossRef]

221. Eberbeck, D.; Wiekhorst, F.; Steinhoff, U.; Schwarz, K.O.; Kummrow, A.; Kammel, M.; Neukammer, J.; Trahms, L. Specific binding of magnetic nanoparticle probes to platelets in whole blood detected by magnetorelaxometry. J. Magn. Magn. Mater. 2009, 321, 1617-1620. [CrossRef]

222. Tsukamoto, A.; Saitoh, K.; Suzuki, D.; Sugita, N.; Seki, Y.; Kandori, A.; Tsukada, K.; Sugiura, Y.; Hamaoka, S.; Kuma, H.; et al. Development of multisample biological immunoassay system using HTS SQUID and magnetic nanoparticles. IEEE Trans. Appl. Supercond. 2005, 15, 656-659. [CrossRef]

223. Sarangi, S.; Tan, I.C.; Brazdeikis, A. Magnetic imaging method based on magnetic relaxation of magnetic nanoparticles. J. Appl. Phys. 2009, 105, 093926. [CrossRef] 
224. Liao, S.H.; Yang, H.-C.; Horng, H.E.; Liu, C.W.; Chen, H.H.; Chen, M.J.; Chen, K.L.; Liu, C.I.; Wang, L.M. Characterizing the field-dependent $\mathrm{T}_{1}$-relaxation and imaging of ferrofluids using high- $\mathrm{T}_{\mathrm{C}}$ superconducting quantum interference device magnetometer in low magnetic fields. J. Appl. Phys. 2012, 112, 123908. [CrossRef]

225. Jia, W.; Xu, G.; Sclabassi, R.J.; Zhu, J.-G.; Bagic, A.; Sun, M. Detection of magnetic nanoparticles with magnetoencephalography. J. Magn. Magn. Mater. 2008, 320, 1472-1478. [CrossRef]

226. Budker, D.; Romalis, M. Optical magnetometry. Nat. Phys. 2007, 3, 227-234. [CrossRef]

227. Kominis, I.K.; Kornack, T.W.; Allred, J.C.; Romalis, M.V. A subfemtoTesla multichannel atomic magnetometer. Nature 2003, 422, 596-599. [CrossRef] [PubMed]

228. Maser, D.; Pandey, S.; Ring, H.; Ledbetter, M.P.; Knappe, S.; Kitching, J.; Budker, D. Note: Detection of a single cobalt microparticle with a microfabricated atomic magnetometer. Rev. Sci. Instrum. 2011, 82, 086112. [CrossRef] [PubMed]

229. Yao, L.; Xu, S. Long-range, high-resolution magnetic imaging of nanoparticles. Angew. Chem. Int. Ed. 2009, 48, 5679-5682. [CrossRef] [PubMed]

230. Garcia, N.C.; Yu, D.; Yao, L.; Xu, S. Optical atomic magnetometer at body temperature for magnetic particle imaging and nuclear magnetic resonance. Opt. Lett. 2010, 35, 661-663. [CrossRef] [PubMed]

231. Hu, Q.; Xu, S. Sequence and chiral selectivity of drug-DNA interactions revealed by force spectroscopy. Angew. Chem. Int. Ed. 2014, 53, 14135-14138. [CrossRef] [PubMed]

232. Ludwig, F.; Heim, E.; Mäuselein, S.; Eberbeck, D.; Schilling, M. Magnetorelaxometry of magnetic nanoparticles with fluxgate magnetometers for the analysis of biological targets. J. Magn. Magn. Mater. 2005, 293, 690-695. [CrossRef]

233. Ludwig, F.; Heim, E.; Menzel, D.; Schilling, M. Investigation of superparamagnetic $\mathrm{Fe}_{3} \mathrm{O}_{4}$ nanoparticles by fluxgate magnetorelaxometry for use in magnetic relaxation immunoassays. J. Appl. Phys. 2006, 99, $08 \mathrm{P} 106$. [CrossRef]

234. Heim, E.; Harling, S.; Pöhlig, K.; Ludwig, F.; Menzel, H.; Schilling, M. Fluxgate magnetorelaxometry of superparamagnetic nanoparticles for hydrogel characterization. J. Magn. Magn. Mater. 2007, 311, 150-154. [CrossRef]

235. Remmer, H.; Roeben, E.; Schmidt, A.M.; Schilling, M.; Ludwig, F. Dynamics of magnetic nanoparticles in viscoelastic media. J. Magn. Magn. Mater. 2017, 427, 331-335. [CrossRef]

236. Ludwig, F.; Heim, E.; Schilling, M. Characterization of superparamagnetic nanoparticles by analyzing the magnetization and relaxation dynamics using fluxgate magnetometers. J. Appl. Phys. 2007, 101, 113909. [CrossRef]

237. Ludwig, F.; Heim, E.; Eberbeck, D.; Schwarz, K.; Trahms, L.; Schilling, M. Comparison and calibration of fluxgate and SQUID magnetorelaxometry techniques for the characterization of magnetic core-shell nanoparticles. IEEE Trans. Magn. 2009, 45, 4857-4860. [CrossRef]

238. Meyer, M.H.F.; Hartmann, M.; Krause, H.-J.; Blankenstein, G.; Mueller-Chorus, B.; Oster, J.; Miethe, P.; Keusgen, M. CRP determination based on a novel magnetic biosensor. Biosens. Bioelectron. 2007, 22, 973-979. [CrossRef] [PubMed]

239. Meyer, M.H.F.; Krause, H.-J.; Hartmann, M.; Miethe, P.; Oster, J.; Keusgen, M. Francisella tularensis detection using magnetic labels and a magnetic biosensor based on frequency mixing. J. Magn. Magn. Mater. 2007, 311, 259-263. [CrossRef]

240. Meyer, M.H.F.; Stehr, M.; Bhuju, S.; Krause, H.-J.; Hartmann, M.; Miethe, P.; Singh, M.; Keusgen, M. Magnetic biosensor for the detection of Yersinia pestis. J. Microbiol. Methods 2007, 68, 218-224. [CrossRef] [PubMed]

241. Rettcher, S.; Jungk, F.; Kühn, C.; Krause, H.-J.; Nölke, G.; Commandeur, U.; Fischer, R.; Schillberg, S.; Schröper, F. Simple and portable magnetic immunoassay for rapid detection and sensitive quantification of plant viruses. Appl. Environ. Microbiol. 2015, 81, 3039-3048. [CrossRef] [PubMed]

242. Hong, H.-B.; Krause, H.-J.; Song, K.-B.; Choi, C.-J.; Chung, M.-A.; Son, S.-W.; Offenhäusser, A. Detection of two different influenza A viruses using a nitrocellulose membrane and a magnetic biosensor. J. Immunol. Methods 2011, 365, 95-100. [CrossRef] [PubMed]

243. Kim, C.-B.; Lim, E.-G.; Shin, S.W.; Krause, H.J.; Hong, H. Magnetic immunoassay platform based on the planar frequency mixing magnetic technique. Biosens. Bioelectron. 2016, 83, 293-299. [CrossRef] [PubMed]

244. Payet, B.; Vincent, D.; Delaunay, L.; Noyel, G. Influence of particle size distribution on the initial susceptibility of magnetic fluids in the Brown relaxation range. J. Magn. Magn. Mater. 1998, 186, 168-174. [CrossRef] 
245. Prieto Astalan, A.; Jonasson, C.; Petersson, K.; Blomgren, J.; Ilver, D.; Krozer, A.; Johansson, C. Magnetic response of thermally blocked magnetic nanoparticles in a pulsed magnetic field. J. Magn. Magn. Mater. 2007, 311, 166-170. [CrossRef]

246. Kriz, K.; Gehrke, J.; Kriz, D. Advancements toward magneto immunoassays. Biosens. Bioelectron. 1998, 13, 817-823. [CrossRef]

247. Barbic, M.; ElBidweihy, H. Effect of magnetic nanoparticle shape on flux amplification in inductive coil magnetic resonance detection. J. Appl. Phys. 2016, 120, 104506. [CrossRef]

248. Donolato, M.; Vavassori, P.; Gobbi, M.; Deryabina, M.; Hansen, M.F.; Metlushko, V.; Ilic, B.; Cantoni, M.; Petti, D.; Brivio, S.; et al. On-chip manipulation of protein-coated magnetic beads via domain-wall conduits. Adv. Mater. 2010, 22, 2706-2710. [CrossRef] [PubMed]

(C) 2017 by the authors. Licensee MDPI, Basel, Switzerland. This article is an open access article distributed under the terms and conditions of the Creative Commons Attribution (CC BY) license (http:/ / creativecommons.org/licenses/by/4.0/). 